\title{
A non-uniform semantic analysis of the Italian temporal connectives prima and dopo
}

\author{
Fabio Del Prete
}

Published online: 28 May 2008

(C) Springer Science+Business Media B.V. 2008

\begin{abstract}
In this paper, I argue that the temporal connective prima ('before') is a comparative adverb. The argument is based on a number of grammatical facts from Italian, showing that there is an asymmetry between prima and dopo ('after'). On the ground of their divergent behaviour, I suggest that dopo has a different grammatical status from prima. I propose a semantic treatment for prima that is based on an independently motivated analysis of comparatives which can be traced back to Seuren (in: Kiefer and Ruwet (eds.) Generative grammar in Europe, 1973). Dopo is analyzed instead as an atomic two-place predicate which contributes a binary relation over events to the sentence meaning. The different semantic treatments of the two connectives provide an explanation for the grammatical asymmetries considered at the outset; interestingly, they also shed some light on other asymmetries between prima and dopo, which are known to hold for the English temporal connectives before and after as well: these asymmetries are related to the veridicality properties, the distribution of NPIs, and the logical properties of these connectives first described in Anscombe (Philos Rev 73:3-24, 1964).
\end{abstract}

Keywords Temporal connectives $\cdot$ Comparatives $\cdot$ Scalar adverbs

\footnotetext{
I am indebted to Andrea Bonomi, Paolo Casalegno, Gennaro Chierchia, and Alessandro Zucchi for discussion of many aspects of the analysis laid out here. I wish to thank two anonymous reviewers for NALS for comments and suggestions as to how to improve this paper.
}

F. Del Prete $(\varangle)$

Dipartimento di Filosofia, Università degli Studi di Milano,

Via Festa del Perdono 7, 20122 Milano, Italy

e-mail: Fabio.DelPrete@unimi.it 


\section{Introduction}

There are many grammatical facts in Italian which show that the temporal connectives prima ('before') and dopo ('after') do not pattern alike. Most of the asymmetries I will focus on have to do with the question whether a certain type of syntactic construction is possible with prima / dopo. In Sect. 2 I will describe the main facts which show the different behaviour of prima and dopo. In Sect. 3 I will draw attention to the grammatical similarities between prima and overt comparatives; more specifically, prima will be shown to pattern like the temporal comparative più presto ('earlier, sooner') in some important respects, while at the same time it will be pointed out that no corresponding similarity holds between dopo and the temporal comparative più tardi ('later'), contrary to what one might expect. Finally, in Sect. 4 I will propose a semantic analysis of prima and dopo which accounts for the empirical data considered at the outset. The semantic analysis that will be proposed is non-uniform: underlyingly, prima has the structure of the temporal comparative più presto, while dopo has the simpler structure of a temporal preposition. The logical forms of sentences with prima and dopo will thus differ in important respects. Interestingly, the analysis turns out to predict certain semantic differences between prima and dopo which have to do with polarity, veridicality, and certain logical properties first described in Anscombe (1964).

\section{Grammatical asymmetries between prima and dopo}

\subsection{Distribution of the phrase di quanto ('of how-much')}

Prima and dopo behave asymmetrically with respect to their distribution with di quanto:

(1)a. Gianni arrivò prima di quanto pensavamo.

Gianni arrived before of how-much thought( $1 \mathrm{pl})$

'Gianni arrived earlier than we thought.'

b. Vent' anni fa si moriva prima di quanto

Twenty years ago one died before of how-much

accade oggi.

happens today

'Twenty years ago people died earlier than it happens nowadays.'

(2)a. *Gianni arrivò dopo di quanto pensavamo.

Gianni arrived after of how-much thought $(1 \mathrm{pl})$

b. *Vent' anni fa si moriva dopo di quanto

Twenty years ago one died after of how-much

accade oggi.

happens today 
As shown by (1), the string di quanto can introduce a clause as internal argument of prima. On the other hand, the unacceptability of (2) shows that di quanto cannot do the same for dopo. ${ }^{1}$

Although, intuitively, the construction prima di quanto has the interpretation of a complex temporal conjunction, it contains the sub-expression di quanto, which has no temporal meaning of its own, being instead one of the conventional means for introducing the second term of comparison in clausal comparatives (i.e. in comparatives with clausal complements). The use of di quanto in comparative sentences is illustrated by the examples below:

(3) Gianni è più alto di quanto pensavamo.

Gianni is more tall of how-much thought(1pl)

'Gianni is taller than we thought.'

(4) Gianni è più alto di quanto sia Leo.

Gianni is more tall of how-much be(3sg subj) Leo

'Gianni is taller than Leo is.'

The occurrence of prima with the comparative introducer di quanto in (1) raises the following question. Given that prima has its ordinary temporal meaning in (1) (the meaning of a binary predicate over temporal entities), what is the semantic contribution of quanto in this context?

In linguistic environments like the ones in (3) and (4) above, quanto is part of expressions which, intuitively, talk about degrees. Namely, while in Gianni è più alto di Leo ('Gianni is taller than Leo') the overt internal argument of the comparative refers to an individual, in Gianni è più alto di quanto sia Leo (literally, 'Gianni is taller than how much Leo is') the internal argument refers to the degree to which Leo is tall. If this intuitive characterization is correct, however, what are the phrases di quanto pensavamo/di quanto accade oggi doing in $(1 \mathrm{a}, \mathrm{b})$ ? Here the internal argument of prima should refer to a time, not a degree. But then, what is an expression of degree doing here?

As a way out of the puzzle, one may propose that the phrases quanto pensavamo/quanto accade oggi actually denote a time in $(1 \mathrm{a}, \mathrm{b})$ (in this proposal, quanto would be analyzed as a temporal operator like 'the time $t$ such that'). But there is no independent evidence that NPs like quanto pensavamo can

\footnotetext{
${ }^{1}$ Use of di quanto as introducer of the internal argument of prima is not always possible. The phrase di quanto mainly co-occurs with complements containing epistemic verbs. It cannot introduce complements with eventive verbs, as is shown by the unacceptability of sentence (i):
}

(i) *Gianni arrivò prima di quanto arrivasse/arrivava Maria.

Gianni arrived before of how-much arrived(3 sg subj/ind) Maria

With eventive verbs, the complementizer che must be used, and the complement clause must accordingly be in the subjunctive mood:
(ii) Gianni arrivò prima che arrivasse Maria.
Gianni arrived before that arrived(3 sg subj) Maria
'Gianni arrived before Maria arrived.'


denote times. We have just seen that, when they occur in comparative sentences, they intuitively denote degrees.

Another possibility for a solution to the puzzle is to keep a uniform analysis of quanto in sentences like (1), (3), and (4), as an operator forming expressions of degree, and to give up the intuitive idea that prima relates times. At first, this would appear to be an extreme solution, since what would be sacrificed in this case is a fundamental intuition about the meaning of prima. A way out of this difficulty, as we will see, is to assume that prima relates degrees of some temporal (gradable) property, so that in the end one can still preserve the intuition that prima relates events with respect to the time dimension.

\subsection{Superlative constructions with the modal predicate possibile ('possible')}

Another asymmetry between prima and dopo concerns their possible occurrence within superlative constructions of the form in (A) in the position of the comparative predicate.

\section{(A) il ('the') + comparative predicate + possibile ('possible')}

I will refer to constructions of this form as 'definite superlatives', because of the occurrence of the definite article in initial position. The basic contrast between our connectives is illustrated by the pair $(5 \mathrm{a}, \mathrm{b})$ below, in which it is shown that prima can occur in definite superlatives in the position of the comparative predicate, while dopo cannot.

(5)a. Leo è tornato il prima possibile.

Leo is returned(past participle) the before possible

'Leo came back at the earliest possible moment.'

b. *Leo è tornato il dopo possibile.

Leo is returned the after possible

What we observe here is that the phrase il prima possibile is a well-formed temporal superlative, having the meaning of the English superlative 'at the earliest possible moment', but the phrase il dopo possibile is ill-formed.

There are other interesting data which show the ability of prima to take on superlative readings, and the inability of dopo to do so. They concern the occurrence of the connective within constructions with modal verb complements, under a superlative interpretation. A sentence with prima exemplifying this type of construction is given in (5c) below, whereas (5d) shows the impossibility for dopo to feature in the same kind of context.

(5)c. Leo è tornato prima che ha potuto.

Leo is return(past participle) before that has can(past participle)

'Leo came back as soon as he could.'

d. *Leo è tornato dopo che ha potuto.

Leo is return(past participle) after that has can(past participle)

(ungrammatical in the interpretation: 'Leo came back as late

as he could.') 
On the one hand, the prima-clause in $(5 \mathrm{c})$ receives a superlative meaning, which is expressed by the English gloss 'as soon as he could'. On the other hand, sentence (5d) turns out to be ungrammatical under a superlative construal: (5d) cannot mean that Leo came back as late as he could, but can only be accepted under a reading in which the deleted clausal complement of the modal verb potere is anaphorically construed at the discourse level, along the lines of a paraphrase like 'Leo came back after he could do it', where 'it' refers to some other action that is contextually salient. Therefore, if (5d) were accepted at all, it would be accepted as an ordinary dopo-sentence, with no superlative reading of the temporal clause.

\subsection{Distribution of expletive negation}

A further puzzling asymmetry between prima and dopo has to do with the possible occurrence of so-called expletive negation in the temporal clause. ${ }^{2}$ Consider the following pair of sentences:

(6)a. Lo fermerai $\begin{aligned} & \text { prima che non faccia } \\ & \text { before that not do(3sg subj) }\end{aligned}$
$\begin{aligned} & \text { Him(cl) } \\ & \text { sciocchezza. }\end{aligned}$
folly
'You will stop him before he does anything silly.'
b. ?' Lo $\quad$ fermerai dopo che non avrà
Him(cl) stop(2sg fut) after that not have(3sg fut) done
qualche sciocchezza.
some folly
'You will stop him after he has not done something silly.'

In (6a), the negation non in the prima-clause of (6a) is naturally understood as expletive negation, i.e. as contributing no negative meaning, as is indicated by the gloss. But the occurrence of non in the dopo-clause in (6b) cannot be an instance of expletive negation, as is also made clear by the gloss. Since the last non must be interpreted as semantic negation, the pragmatic anomaly of (6b) follows (in view of the fact that it is not a normal action to stop someone after he has not done silly things).

It is not always possible to have an expletive negation in a clause with prima. A rough generalization is that this kind of negation is allowed only in

\footnotetext{
${ }^{2}$ I follow Espinal (2000) in characterizing the phenomenon of expletive negation by the fact that a negative marker (like the adverb non), which lexically contributes negative meaning in normal cases, does not affect the proposition expressed by the sentence in which it occurs. According to this characterization, the negative marker non in (ii) is an instance of expletive negation, since the proposition expressed by (ii) is the same as the one expressed by (i), where the negative marker non does not occur.
}

(i) Lo fermai prima che facesse sciocchezze. him(cl) stopped(1st sg) before that $\operatorname{did}(3 \mathrm{rd} \mathrm{sg}, \mathrm{subj})$ follies

(ii) Lo fermai prima che non facesse sciocchezze. him(cl) stopped(1st sg) before that not $\operatorname{did}(3 \mathrm{rd} s g$, subj) follies

'I stopped him before he did anything silly.' 
nonfactual prima-clauses (namely, in prima-clauses which are assumed to be false in the world of the context). For instance, (6a) must be interpreted as saying that you will stop him in order to prevent him from doing any foolish thing, i.e. so as to make it false that he will do foolish things. If we take a sentence similar to (6a), but with a factual prima-clause, we find that insertion of the negative marker non in the temporal clause would be interpreted as contributing a negative meaning. For example, consider an utterance of (6c) in a context in which the future event of Leo's leaving for Rome is taken for granted.

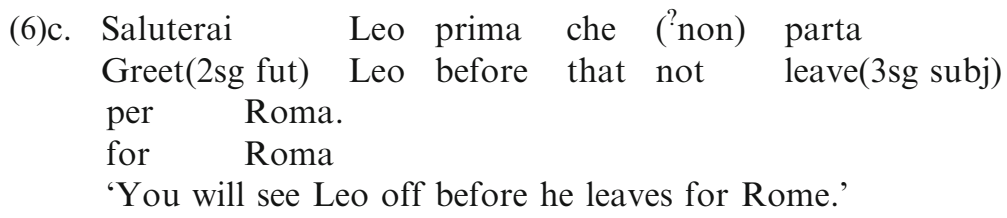

The insertion of non in the temporal clause would make the sentence deviant, since the negative marker could not be interpreted as expletive negation, and the resulting semantically negative clause would make no sense in this case. This observation casts doubts on purely structural characterizations of the licensing conditions of expletive negation. Anyhow, the difference between prima and dopo remains: the former can license expletive negation in its clause under certain conditions, while the latter cannot.

\subsection{Distribution of $n$-words and other NPIs}

Before presenting some data concerning the interpretation of so-called $n$-words in temporal clauses with prima and dopo, I will describe the behaviour of these words in Italian. ${ }^{3}$ The following paradigm, involving the $n$-word nessuno ('no-one'), illustrates the main properties of Italian $n$-words:

(7)a. Leo non ha visto nessuno.
Leo not has seen no-one
'Leo hasn't seen anyone.'
b. Nessuno ha visto Leo.
No-one has seen Leo
'Nobody has seen Leo.'
c. * Leo ha visto nessuno.
Leo has seen no-one
d. Nessuno non ha visto Leo.
No-one not has seen Leo
'Nobody hasn't seen Leo.'

From the paradigm in (7), the $n$-word nessuno seems to have a double nature: in $(7 \mathrm{a}, \mathrm{c})$ it behaves as an ordinary NPI, since it appears to require a negative context, within which it is interpreted as an existential quantifier (much like anyone in English); however, in ( $7 \mathrm{~b}, \mathrm{~d})$ it behaves as a negative universal

\footnotetext{
${ }^{3}$ For the concept of $n$-word, I refer the reader to Laka Mugarza (1990).
} 
quantifier (much like nobody in English), carrying a negative meaning of its own and thus inducing the double-negation effect displayed in (7d). At a descriptive level, we can say that Italian $n$-words are characterized by the double interpretation option shown in (7): they are licensed as NPIs in certain negative contexts, and as negative universal quantifiers in other contexts.

The data that I'm going to present now go against an observation by Corblin and Tovena (2003). According to them, Italian prima, unlike French avant and Portugese antes, does not license $n$-words as NPIs. In fact, the sentences in (8) below show that the $n$-words nessuno ('no-one') and niente ('nothing') can be interpreted as existential quantifiers within their clauses, just as 'anyone' and 'anything' in the corresponding English glosses. Sentences $(8 \mathrm{a}, \mathrm{b})$ attest an existential interpretation of nessuno and niente in subject preverbal and postverbal position, whereas (8c) exemplifies an existential interpretation of nessuno in object position.

(8)a. Ho scoperto io quel locale, prima che nessuno di Have(1sg) discovered I that place, before that no-one of voi vi avesse mai messo piede. you there(cl) had(subj) ever put foot 'I discovered that place, before anyone of you had ever set foot there.'

b. $\mathrm{Me}$ ne andai prima che accadesse

Self(cl) ne(cl) went(1sg) before that happened(3sg subj) niente di spiacevole. nothing of unpleasant 'I left before anything unpleasant happened.'

c. La polizia fermò l' autista ubriaco, prima che the police stopped the driver drunk before that investisse nessuno. ran-over(3sg subj) no-one 'The police stopped the drunk driver before he ran over anyone.'

The following literary examples, taken from two 19th century Italian novelists, also show NPI interpretations of nessuno in subject preverbal position:

(8)d. Legatevi le scarpe bene, e, prima che nessuno vi tie-self $(2 \mathrm{pl})$ the shoes well and before that no-one you(cl) veda, tornate di dove siete venuto. ${ }^{4}$ see $\operatorname{return}(2 \mathrm{pl})$ of when $\operatorname{are}(2 \mathrm{nd} \mathrm{pl})$ come(past participle) 'Tie your shoelaces well and, before anyone sees you, go back to the place where you came from.'

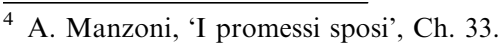




\section{e. [...] e padron 'Ntoni soleva rispondere prima che nessuno and master 'Ntoni used answer(inf) before that no-one avesse aperto}

had opened

bocca- Un quintale, o un quintale e venticinque-. ${ }^{5}$ mouth- One quintal or one quintal and twenty-five'[...] and master 'Ntoni used to answer before anyone had said a word One quintal, or one quintal and a quarter-',

Some researchers have argued that nessuno is invariably an NPI, i.e. it doesn't have the meaning of a negative universal quantifier (like no one in English), but only that of a positive existential quantifier which can be licensed in downward entailing (DE) contexts exclusively (like the NPI anyone). ${ }^{6}$ According to this hypothesis, negative existential meaning in sentences like (7b) above comes from the fact that nessuno is still in the scope of an independent negative operator at an underlying level. In Sect. 4.3, I will assume that this account is correct to the extent that nessuno only contributes existential meaning to the sentence in which it occurs (although, for the time being, I'll keep referring to the existential meaning and the negative existential meaning of nessuno for descriptive purposes). Notice, however, that the hypothesis that what licenses nessuno is a DE environment needs to be refined. Indeed, nessuno is not licensed in all DE contexts. Its licensing conditions entail something more specific than bare DE-ness. For example, in (9a) below nessuno cannot be interpreted as a positive existential. In this context, it must be interpreted as a negative universal $\forall \neg$ (i.e., as the English nobody). This fact is in striking contrast with the reading of $(9 b)$, where anyone obtains its NPI interpretation as positive existential, with scope bounded to the antecedent of the conditional.

(9)a. Se nessuno ti incontra, dimmelo.

if no-one you meet tell-me-it

'If nobody runs into you, tell me.'

b. If anyone runs into you, tell me.

Moreover, positive existential nessuno is not licensed in DE contexts such as the scope of DPs with the determiner pochi ('few'). This is shown by the unacceptability of $(9 \mathrm{c})$ :

\footnotetext{
${ }^{5}$ G. Verga, 'I Malavoglia', Ch. 10.

${ }^{6}$ See Laka Mugarza (1990) for a proposal of this kind. Against proponents of the ambiguity hypothesis such as Longobardi (1986) and Zanuttini (1989), who claim that $n$-words like Italian nessuno are lexically ambiguous between an NPI existential meaning (attested in negative sentences like Leo non ha visto nessuno - 'Leo hasn't seen anyone') and a negative universal meaning (apparently attested in sentences like Nessuno ha visto Leo - 'No one has seen Leo'), she argues that "there is only one set of $n$-words in the lexicon of Spanish, Catalan, Italian and Portuguese, and that these items are indeed [Negative] Polarity items (and therefore existential quantifiers)." (Laka Mugarza 1990, p. 115)
} 
(9)c. *Poche persone hanno visto nessun film. few persons have seen no-one film

This sentence cannot have the interpretation of the English sentence 'Few persons have seen any film'; it is simply anomalous.

These facts about nessuno need not be too surprising. It is well known that there are different kinds of NPIs, some of which can only be licensed in specific DE contexts. ${ }^{7}$ For instance, a minimizer like fare un cavolo (literally 'to do a cabbage') is not licensed in all DE contexts, as shown by the contrast between (9d) and (9e) below, whence we can conclude that it places further restrictions on the environments in which it can occur with its NPI meaning ('to do anything').

(9)d. *Poche persone hanno fatto un cavolo.
few persons have done a cabbage
(only acceptable in the literal reading 'Few persons did a cabbage.')
e. Nessuno ha fatto un cavolo.
nobody has done a cabbage
'Nobody did anything.'

For the time being, I will not go into a proper characterization of the contexts in which different kinds of NPIs can occur. What matters at this point is the generally agreed-upon observation that NPIs do not pattern alike. ${ }^{8}$

If we now look at dopo-clauses, we see that nessuno is interpreted in a different way with respect to prima-clauses. Consider for instance sentence (10a):

$\begin{array}{llllll}\text { (10)a. Ho } & \text { scoperto } & \text { io quel locale, } & \text { dopo che nessuno } \\ \text { Have(1sg) } & \text { discovered } & \text { I that } & \text { place, } & \text { after that no-one } \\ \text { di voi } & \text { vi } & \text { aveva } & \text { mai } & \text { messo pode. } \\ \text { of you } & \text { there(cl) } & \text { had } & \text { ever } & \text { put } & \text { foot }\end{array}$

'I discovered that place, after no one of you had ever set foot there.'

\footnotetext{
${ }^{7}$ See Zwarts (1998) for a typology of NPIs in which different licensing conditions are taken to characterize different classes of polarity items.

${ }^{8}$ In Sect. 4.3 below, I will assume that nessuno can only be licensed in the semantic scope of an antiadditive operator. An anti-additive operator is an operator which satisfies De Morgan's first law. The following formal definition is adapted from Zwarts (1998):
}

An operator Op defined over an algebra of sets $\mathcal{A}$ is said to be anti-additive iff for each two elements $\mathrm{X}$ and $\mathrm{Y}$ of $\mathcal{A}$ :

(i) $\mathrm{Op}(\mathrm{X} \cup \mathrm{Y})=\mathrm{Op}(\mathrm{X}) \cap \mathrm{Op}(\mathrm{Y})$

In the algebraic typology set out by Zwarts, a DE operator is defined as an operator which satisfies the left-to-right component of (i), namely:

(ii) $\mathrm{Op}(\mathrm{X} \cup \mathrm{Y}) \subset \mathrm{Op}(\mathrm{X}) \cap \mathrm{Op}(\mathrm{Y})$

As is clear from these definitions, the set of anti-additive operators is included in the set of DE operators.

This assumption will make it possible to explain the unacceptability of sentences like (9c) in the main text; in sentence (9c), the DP poche persone ('few persons') can't license the $n$-word nessuno, because it is not an anti-additive operator. 
In (10a) nessuno is interpreted as the negative universal quantifier 'no one'. This is the same interpretation that one can observe when nessuno occurs in matrix clause pre-verbal position, as in (7b), repeated here as (10b):

(10)b. Nessuno ha visto Leo.

'Nobody has seen Leo.'

Be $n$-words existential NPIs (as I will assume), or be they lexically ambiguous between an NPI interpretation and a negative universal interpretation, the conclusion we can draw from the contrast between (8) and (10a) is that there is nothing in the underlying syntactic structure of a dopo-sentence that licenses the n-word nessuno in its interpretation as the NPI 'anyone'. Whatever licenses the occurrence of nessuno in the dopo-clause of (10a) must be the same factor which licenses its occurrence in sentence (10b): in both cases, nessuno gets the negative universal interpretation of 'no one'. This fact is in striking contrast with the facts about prima which we have considered in (8) above.

If we see $n$-words as being just a kind of NPIs, ones that impose stronger requirements on their environments than simple DE-ness, the ability of prima to license the $n$-words nessuno and niente leads us to expect that prima could also license "weaker" NPIs such as alcuno ('anyone') and alcunché ('anything'). Indeed, this is what we observe in sentences $(11 \mathrm{a}, \mathrm{b})$ :
(11)a. Andai
via prima che arrivasse
Go(1sg, past ind) away before that arrive(3sg, past subj)
alcuno di loro.
anyone of them
'I went away before anyone of them arrived.'
b. Andai via prima che accadesse alcunché. Go(1sg, past ind) away before that happen( $3 \mathrm{sg}$, past subj) anything 'I went away before anything happened.'

By contrast, dopo licenses neither alcuno nor alcunché. This is shown by the ungrammaticality of $(11 \mathrm{c}, \mathrm{d})$ :

(11)c. *Sono andato via dopo che è arrivato alcuno di loro.

(I) am gone away after that is arrived anyone of them

d. *Sono andato via dopo che è accaduto alcunché.

(I) am gone away after that is happened anything

The conclusion we can draw from the data above is that prima is a NPI-licenser (it licenses "ordinary" NPIs as well as $n$-words), but dopo is not (it licenses neither $n$-words nor ordinary NPIs).

\subsection{Association with the scalar adverb ancora}

Yet another interesting asymmetry which distinguishes prima from dopo arises in connection with the availability of the construction [ancora + prima/dopo], taken in a specific scalar interpretation. Before considering the relevant data, 
I have to note that ancora is ambiguous between the iterative interpretation of 'again' and a scalar interpretation which ranges from the temporal interpretation of 'still' (as in Sta ancora piovendo - 'It is still raining') to a non-temporal interpretation close to 'even' (as in Leo è ancora più alto di Teo-'Leo is even taller than Teo'). In the particular meaning of the construction [ancora + connective] that I am interested in, the adverb ancora is interpreted in a way similar to the focus particle 'even'. Let's now consider the different interpretations of sentences (12a, b).

(12)a. Gianni è tornato ancora prima che facesse
Gianni is returned ancora before that did(3sg, subj) dark
'Gianni came back even earlier than it got dark.'
'Gianni came back again before it got dark.'
b. Gianni è tornato ancora dopo che ha fatto buio.
Gianni is returned ancora after that has done dark
'Gianni came back again after it got dark.'

Sentence (12a) has two readings. In the first reading (Reading 1 above), which is prosodically signalled by pitch accent on prima, the word ancora is intuitively related to the temporal connective prima, with which it forms a phonological unit (evidence for this relationship is given by the possibility of having truncation of the final vowel of ancora, with subsequent formation of the sequence ancor prima as a phonological constituent). The meaning of ancora prima in this reading corresponds to the meaning of the English phrase even earlier. The sentence suggests that Gianni came back quite early, in some contextually determined sense. I'll refer to the implication of the high degree of earliness for the event of Gianni's return as the 'intensification effect' triggered by scalar ancora.

In the second reading of (12a) (Reading 2 above), which is prosodically signalled by a pitch accent on ancora, we see that the adverb gets the iterative meaning of 'again' (significantly, the formation of the phonological constituent ancor prima, with truncation of the final vowel of ancora, is not a possible option under this reading).

Let's now look at (12b). For some reason, this sentence has only the iterative reading. In this context, ancora does not form a semantic unit with the temporal connective dopo (on the phonological side, we cannot have a possible unit ancor dopo, which would parallel the unit ancor prima). As a result, while (12a) has an 'even earlier than'-reading, (12b) lacks a corresponding 'even later than'-reading.

\subsection{Summing up}

In the preceding sections, we have focused on certain puzzling differences between prima and dopo. These differences are unexpected, insofar as we think of the two connectives as belonging to the same grammatical category and having the same kind of denotation. In the next section, I will point out some similarities holding between prima and comparatives with respect to the grammatical facts considered in Sects. 2.1-5. 


\section{Grammatical similarities between prima and comparatives}

All the linguistic constructions involving prima that I have described in Sect. 2 also occur in Italian sentences with comparatives, as is shown in the examples reported in Sect. 3.1 below. This indicates that there is a grammatical similarity between prima and comparatives which is not shared by dopo, since, as we saw, dopo does not occur in the constructions described in Sect. 2.

3.1 Some grammatical facts about comparatives

\subsubsection{Distribution of the phrase di quanto}

We have seen that prima, unlike dopo, can occur with the phrase di quanto. The same is true of clausal comparatives, as the following example shows ${ }^{9}$ :

Gianni è più alto di quanto pensavamo.
Gianni is more tall of how-much thought(1pl)
'Gianni is taller than we thought'

'Gianni is taller than we thought'

\subsubsection{Superlative constructions with the modal predicate possibile}

We have observed that prima can occur in the definite superlative phrase il prima possibile (with the same meaning as the English phrase at the earliest possible moment). The same is also true of comparatives, either synthetic, like peggiore ('worse'), or analytic, i.e. of the form [più + predicate]. These occurrences are shown by the sentences in (14).

(14)a. Ha scritto la peggiore recensione possibile.
Has written the worse review
'He wrote the worst possible review.'
b. Ha sparato il più in alto possibile.
Has shot the more in high possible
'He shot the highest possible.'

\subsubsection{Distribution of expletive negation}

As we saw, expletive negation is licensed in some prima-clauses. Now, one can find instances of the same phenomenon in comparative clauses as well. Sentence (15) is a case in point:

\footnotetext{
${ }^{9}$ Actually, the construction with di quanto is the most common for clausal comparatives in contemporary Italian, where use of the complementizer che ('that') to introduce the comparative clause is much less common than in the past. As Donati $(2000$, p. 6) puts it, "La costruzione con di quanto sovrasta nettamente le altre quanto a diffusione nell'uso odierno. Anzi, a giudizio di molti parlanti [...], rimane l'unica alternativa interamente produttiva." ('The construction with di quanto definitely prevails over the others with respect to frequency in current use. Actually, according to many speakers [...], it remains the only option which is wholly productive.')
} 
(15) Sparerà più in alto che non pensi.

Shoot(3sg fut) more in high that not think(2sg subj)

'He will shoot higher than you think.'

\subsubsection{Distribution of $n$-words}

Comparatives and prima pattern alike also with respect to the licensing of $n$-words as NPIs with existential force. Indeed, in the comparative clause of (16) the $n$-word nessuno occurs with the meaning of the NPI 'anyone'.

(16) Maria mangia più biscotti di quanti ne
Maria eats more biscuits of how-many of-them(cl) eats(subj)
nessun altro.
no-one else
'Maria eats more biscuits than anyone else does.'
(Donati 2000)

\subsubsection{Association with the scalar adverb ancora}

The adverb 'ancora', which, as we have seen, can associate with prima to produce what I called 'intensification effect', can also associate with comparatives, giving rise to the same effect. This is shown by (17):

(17) Gianni ha guadagnato ancora più soldi di Mario. Gianni has earned ancora more money of Mario 'Gianni earned even more money than Mario.'

A natural inference one can draw from an utterance of (17) is that Gianni must have earned quite a remarkable amount of money. This is the intensification effect triggered by scalar ancora.

\subsection{Two claims about prima and dopo}

The data considered in Sects. 2-3.1 show that prima shares certain properties with comparatives, while dopo does not. In this section, I will argue for the following more specific claims:

(C1) Prima is a temporal comparative, with the same LF-structure as the overt comparative più presto ('earlier').

(C2) Dopo is not a temporal comparative, but a temporal preposition contributing a binary relation over events to the sentence meaning.

As for (C1), the empirical basis for analyzing prima in the same way as the temporal comparative più presto includes the following data, where the 
alternation between prima and più presto does not involve any change in sentence meaning ${ }^{10}$ :

(18)a. Vieni

prima/più presto che puoi.

Come(2sg) before / more early that can(2sg)

'Come as soon as you can.'

b. *Vieni dopo che puoi.

Come(2sg) after that can(2sg)

c. Vieni più tardi che puoi.

Come(2sg) more late that can(2sg)

'Come as late as you can.'

(19)a. Quanto prima / più presto arriverai, tanto più sarai favorito.

'The earlier you will arrive, the more you will be favoured.'

b. *Quanto dopo arriverai, tanto più sarai favorito.

c. Quanto più tardi arriverai, tanto più sarai favorito.

'The later you will arrive, the more you will be favoured.'

(20)a. Verrò prima / più presto di quanto tu pensi.

'I will come earlier than you believe.'

b. *Verrò dopo di quanto tu pensi.

c. Verrò più tardi di quanto tu pensi.

'I will come later than you believe.'

(21)a. L'estate di quest'anno arrivò prima / più presto dell'estate dell'anno scorso.

'This year's summer arrived earlier than last year's summer.'

b. *L'estate dell'anno scorso arrivò dopo dell'estate di quest'anno.

c. L'estate dell'anno scorso arrivò più tardi dell'estate di quest'anno.

'Last year's summer has arrived later than this year's summer.'

Note that for dopo we cannot have similar equivalences with più tardi ('later'), since, as we show in the b-sentences, dopo cannot occur in these environments (at least not with the same meaning as più tardi). The sentence with prima in (21a) is particularly interesting, as it clearly shows that prima can express a relation which does not coincide with the precedence relation between the events explicitly mentioned in the sentence: the sentence does not mean that this year's summer temporally precedes last year's. The same is also true for the corresponding sentence with più presto in (21a).

If we analyse the semantic contribution of prima as being the same as that of the temporal comparative più presto, we should expect that prima could also express a relation other than that of temporal precedence. Indeed, the comparative più presto does not necessarily express the relation of temporal precedence, since the gradable predicate presto is not bound to locate events

\footnotetext{
${ }^{10}$ The b-sentences in (18)-(21) are all ungrammatical in the readings expressed by the English glosses corresponding to the sentences with the comparative più tardi ('later'). Each of the b-sentences contrasts with the corresponding c-sentence, which has the overt comparative più tardi in place of dopo.
} 
with respect to a time axis. Some examples which clearly show different semantic contributions of the adverb presto are given in (22)-(24) below. As these sequences show, presto has a complex meaning which approximately covers the meanings of the English adverbs early, soon, and fast.

(22) Carlo è andato in ufficio presto (alle 8). Ivano ci è andato ancora più presto di Carlo (alle 7).

'Carlo went to his office early (at 8 p.m.). Ivano went to his office even earlier than Carlo (at 7 p.m.).'

(23) Carlo ha fatto presto a dare il talk (lo ha dato in 25 minuti). Ivano ha fatto ancora più presto di Carlo (lo ha dato in 20 minuti).

'Carlo did fast to give his talk (he gave it in 25 minutes). Ivano did even faster than Carlo (he gave it in 20 minutes).'

(24) Carlo l'anno scorso è andato in vacanza presto (a giugno). Ivano quest'anno ci è andato ancora più presto (a maggio).

'Last year Carlo went on holidays early (on June). This year, Ivano went on holidays even earlier (on May).'

In each one of the sequences (22)-(24), the temporal comparative più presto can be replaced by the temporal connective prima, without bringing about any change in meaning. Discourses $\left(22^{\prime}\right)-\left(24^{\prime}\right)$ are what we obtain by doing the relevant substitutions:

$\left(22^{\prime}\right)$ Carlo è andato in ufficio presto. Ivano ci è andato ancora prima di Carlo.

'Carlo went to his office early. Ivano went to his office even earlier than Carlo.'

(23') Carlo ha fatto presto a dare il talk. Ivano ha fatto ancora prima di Carlo. 'Carlo did fast to give his talk. Ivano did even faster than Carlo.'

(24') Carlo l'anno scorso è andato in vacanza presto (a giugno). Ivano quest'anno ci è andato ancora prima (a maggio).

'Last year Carlo went on holidays early (on June). This year, Ivano went on holidays even earlier (on May).'

If prima is indeed interpreted as the comparative più presto, the variation in meaning of prima across (22'), (23'), (24') does not come as a surprise.

Diachronic evidence for the claim that prima is interpreted as the comparative più presto comes from considering what we may call 'uses of prima on preference/likelihood scales'. ${ }^{11}$ Here are some examples attesting these particular uses:

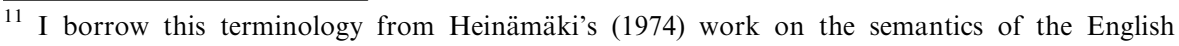
temporal connectives.
} 
(25)

$\begin{array}{llllll}\mathrm{Si} & \text { mangerà } & \text { le } & \text { scarpe } & \text { prima } & \text { di riconoscere } \\ \text { Self(cl) } & \text { eat(3sg fut) } & \text { the } & \text { shoes } & \text { before } & \text { of } \\ \text { il } & \text { suo } & \text { errore. } & & & \\ \text { the } & \text { his/her } & \text { error } & & \end{array}$

'He/she will eat his/her shoes before acknowledging his/her fault.'

(26) Le mucche voleranno prima che Gianni

the cows fly( $3 \mathrm{pl}$ fut) before that Gianni

capisca questo teorema.

understand(3sg subj) this theorem

'Cows will fly before Gianni understands this theorem.'

The role of prima in (25) is not to specify a temporal ordering of the mentioned events, but rather to assign a higher degree of subjective preference to the event of eating one's own shoes than to the event of acknowledging one's own error. Accordingly, (25) could be paraphrased as 'She would rather eat her shoes than acknowledge her error'. In (26) as well, prima does not express temporal precedence of the main clause event with respect to the subordinate clause event; in this case, the intuitive role of prima is to assign a higher degree of likeliness to the event of cows flying than to the event of Gianni's understanding the theorem. Now, it is true that the comparative più presto cannot be substituted for prima in (25)-(26) salva grammaticalitate, and the reason is that syntactically più presto cannot combine with infinitive $d i$-clauses or with finite che-clauses (except in superlatives, such as the one we considered in (18a) above). However, if my claim that prima underlyingly is interpreted as più presto is correct, we should expect that if più presto could syntactically combine with a che-clause, it should be able to occur to convey an ordering on a preference/likelihood scale as well. Indeed, this is exactly the case in 16th century Italian, where combinations of più presto with checomplements were quite frequent. Examples of such uses are shown in the following sentences:

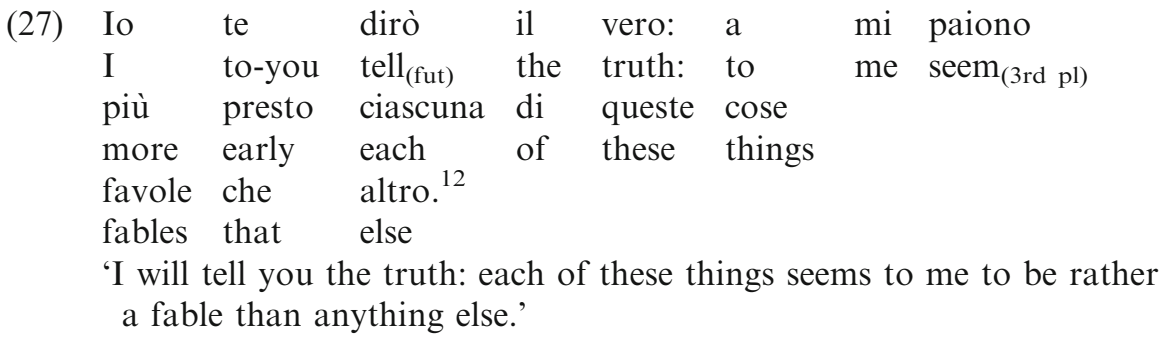

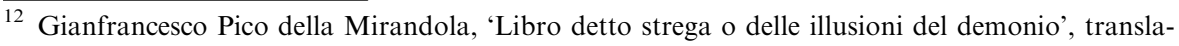
tion from Latin by Leandro Alberti, 1524. 
(28) Certamente disse il Moro, s' egli è vero quello, che certainly said the More, if he is true that, which nelle ragioni civili si scrive, che è, Qui tacet, in-the arguments public one writes, that is, Qui tacet, consentire videtur, il silentio mio ha più presto consentire videtur, the silence my has more early confermato lo statuto vostro, che condannato. ${ }^{13}$ confirmed the statute your, that condemned 'Certainly, More said, if that is true, which people write in public arguments, that is, 'Qui tacet, consentire videtur', then my silence has rather confirmed your statute than condemned it.'

Now let's turn to claim (C2). According to its negative part, dopo is not underlyingly interpreted as a temporal comparative. The comparative più tardi ('later') arguably would be the most likely candidate for a hypothetical analysis of dopo as a temporal comparative. If dopo bore to piu tardi the same similarity which prima bears to più presto, the constructions dopo di quanto and dopo che puoi should be able to mean the same as the expressions più tardi di quanto ('later than') and più tardi che puoi ('as late as you can'), respectively. But we have seen in (18b) and (20b) above that dopo di quanto and dopo che puoi are not grammatical, at least not in the interpretations expressed by the English glosses 'later than' and 'as late as you can'.

The positive part of (C2), according to which dopo is a temporal preposition, deserves some comments. In this connection, I would like to exploit a parallel between dopo on the one hand, and spatial prepositions like sopra ('above'), sotto ('under'), a sinistra ('to the left'), a destra ('to the right') on the other. What is common to these spatial expressions is their inherent directionality. Each of them is associated with a particular dimension, and specifies a direction over this dimension. For instance, sopra is associated with a spatial vertical dimension, and specifies a particular direction over it; when we say that an object $x$ is $n$ meters sopra ('above') another object $y$, we mean that $x$ is $n$ meters far away from $y$ in the direction specified by sopra; when we say that an object $x$ is $n$ meters sotto ('under') another object $y$, we mean that $x$ is $n$ meters far away from $y$ in the direction specified by sotto; when we say that an object $x$ is $n$ meters a sinistra/destra ('to the left/right') of another object $y$, we mean that $x$ is $n$ meters far away from $y$ in the direction specified by a sinistra/destra.

My suggestion is that the temporal conjunction dopo behaves in a way similar to spatial prepositions/adverbials like sopra, sotto, and a sinistra/destra (di). More precisely, I suggest that dopo is associated with a particular

\footnotetext{
13 Letter from the Cardinal Niccolò Schönberg to the Cardinal Marino Caracciolo about the trial and the death of Thomas More, August 12, 1535.
} 
dimension, the time dimension, and that it specifies a direction over this dimension, namely the direction corresponding to chronological succession. ${ }^{14}$

\section{Proposal for a comparative semantics of prima and an atomic semantics of dopo}

\subsection{Semantic analysis of prima}

In order to implement a semantic analysis of prima based on claim (C1), I need to make explicit some assumptions about the syntax and semantics of comparative constructions.

Following Cresswell (1976) and von Stechow (1984), among others, I will treat gradable predicates semantically as binary predicates having an argument place for degrees. Gradable predicates shall thus denote relations between individuals and degrees. To give an example, the semantic representation of a simple predication like (29) will be $\left(29^{\prime}\right)$ :

Leo è alto.

'Leo is tall.'

alto'(Leo, $d)$

Unlike in Cresswell's proposal, however, the role of the degree term $d$ in $\left(29^{\prime}\right)$ will not be to specify the degree of Leo's tallness. The semantic value of $d$ in a particular utterance of (29) will be a degree representing the contextually relevant standard of tallness. The degree term $d$ in $\left(29^{\prime}\right)$ can thus be thought of as a variable whose value is fixed by the context of utterance. The question whether Leo is tall or not can be tackled only after a certain degree has been fixed by the context as representing the relevant standard of tallness.

${ }^{14}$ One could argue that modifiability by Measure Phrases (MPs) is evidence for the underlying comparativity of the prepositions sopra and sotto on the basis of sentences (i)-(iii) below, which show that these prepositions, like comparatives, can be modified by a spatial MP like ' $30 \mathrm{~cm}$ ':

(i) Il chiodo è infisso $30 \mathrm{~cm}$ sopra la mensola.

the nail is infixed $30 \mathrm{~cm}$ over the shelf

'The nail is infixed $30 \mathrm{~cm}$ over the shelf.'

(ii) L' anfora è situata $30 \mathrm{~cm}$ sotto la superficie dell' acqua. the amphora is situated $30 \mathrm{~cm}$ under the surface of-the water

'The amphora is situated $30 \mathrm{~cm}$ under the surface of the water.'

(iii) Gianni è $30 \mathrm{~cm}$ più alto di Piero.

Gianni is $30 \mathrm{~cm}$ more tall of Piero

'Gianni is $30 \mathrm{~cm}$ taller than Piero.'

However, a sinistra and a destra can also be modified by spatial MPs, as the examples in (iv) show, though it is implausible to assume that they are comparatives underlyingly:

(iv) L'attaccapanni è situato 2 metri a sinistra / a destra della lampada.

'The hatstand is situated 2 meters to the left of the lamp.' 
The interpretation of relational formula $\left(29^{\prime}\right)$ is based on the following assumptions:

(a1) For every gradable predicate $P$, there exists a non-empty linearly ordered set $\mathrm{DEG}_{P},{ }^{15}$ whose elements are degrees of $P$-ness (for example, the predicate 'tall' will have a corresponding linearly

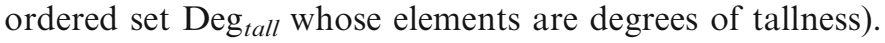

(a2) For every gradable predicate $P, f_{P}$ is a measure function whose domain, $\operatorname{Dom}\left(f_{P}\right)$, is the set of all (non-degree) objects to which $P$ can be meaningfully applied, and whose codomain, $\operatorname{Codom}\left(f_{P}\right)$, is the set $\mathrm{DEG}_{P}$ (for example, for the predicate 'tall' there exists a measure function $\mathrm{f}_{\text {tall }}$ such that for every individual $a$ to which 'tall' can be appropriately applied $\mathrm{f}_{\text {tall }}(a)$ is a height).

(a3) For any object $x \in \operatorname{Dom}\left(f_{P}\right), f_{P}(x)$ is the exact measure of $x$ 's $P$-ness (for example, $f_{\text {tall }}(a)$ is the height of $a$ ).

(a4) For any gradable predicate $P$, the following equivalence holds:

$$
\text { (Equi) } P(x, d) \equiv f_{P}(x) \geq_{P} d
$$

( $\geq_{P}$ ' denotes the relation of being greater than or equal to, restricted to the set $\mathrm{DEG}_{P}$; the value of $d$ is a degree $\mathrm{d} \in \mathrm{DEG}_{P}$ such that $f_{P}(x)$ is greater than or equal to d; for example, $P(a, d)$ is true if and only if the height of $a$ is greater than or equal to the standard of tallness, i.e. the degree, denoted by $d$.)

\footnotetext{
(c1) $\forall x[x \mathrm{R} x]$ (reflexivity)

(c2) $\forall x \forall y[(x \mathrm{R} y \wedge x \neq y \rightarrow \neg y \mathrm{R} x)]$ (antisymmetry)

(c3) $\forall x \forall y \forall z[(x \mathrm{R} y \wedge y \mathrm{R} z) \rightarrow x \mathrm{R} z]$ (transitivity)

(c4) $\forall x \forall y[x \mathrm{R} y \vee y \mathrm{R} x \vee x=y]$ (connectedeness)
}

15 A set $\mathrm{S}$ is said to be linearly ordered by a two-place relation $\mathrm{R}$ if $\mathrm{R}$ is a relation defined over $\mathrm{S}$ which satisfies the following conditions (see Landman 1991, p. 84):

A relation $\mathrm{R}$ which satisfies (c1)-(c4) is said to be a linear order (or total order).

The assumption that the set of degrees $\mathrm{DEG}_{P}$ associated with a gradable predicate $P$ be linearly ordered is standard within scalar analyses. In order to avoid unnecessary deviations, I also assume that the ordering relation for any set of degrees is a linear order, although I should mention that a scalar analysis like the one I'm going to propose does not hinge upon such an assumption. A weaker assumption would do equally well, namely the assumption that the ordering relation $\mathrm{R}$ be tree-like (this could be achieved by replacing the connectedness condition with the weaker conditions $\forall x \forall y \forall z[(x \mathrm{R} z \wedge y \mathrm{R} z) \rightarrow(x \mathrm{R} y \vee y \mathrm{R} x \vee x=y)]$ and $\forall x \forall y \exists z[z \mathrm{R} x \wedge z \mathrm{R} y]$; see Landman 1991, p. 103). This observation turns out to be relevant in connection with the analysis of the degree predicate presto, which is taken here to underlie the temporal connective prima. Indeed, it will be assumed that the set of degrees associated with presto is the set of time instants $\mathrm{T}$, taken in its natural order of temporal precedence. Now, one might not want to superimpose a linear order over $\mathrm{T}$, insofar as one holds a preference for a branching (tree-like) representation of time. From this point of view, the assumption that degrees be linearly ordered might be judged too strong. I will return to this issue later on. 
It is immediate to see that the following monotonicity principle holds true:

$$
\text { (MP) } \forall d \forall d^{\prime}\left[P(x, d) \rightarrow\left[d \geq_{P} d^{\prime} \rightarrow P\left(x, d^{\prime}\right)\right]\right]
$$

This principle expresses the downward monotonicity of the relation of satisfaction of a gradable property: it requires for example that if $a$ is tall for the standard $d$, then if $d$ is greater than $d^{\prime}$, $a$ is also tall for the standard $d^{\prime}$.

The comparative marker più ('more') will be treated as a quantifying determiner over degrees: it combines with an expression denoting a set of degrees, and yields a generalized quantifier over degrees. The comparative clause provides the internal argument for più, whereas the material in the matrix clause provides the argument for the generalized quantifier formed by the combination of più with its internal argument. The semantic value of the comparative clause will be a set of degrees. In order to obtain this semantic value, I will analyze the comparative introducer quanto in a way similar to the way PP internal subjects are analyzed in Heim and Kratzer (1998). According to their proposal, PP internal subjects are vacuous pronouns base-generated in the Spec position of PP. These subjects undergo QR at LF for type reasons and in this way yield a $\lambda$-abstraction over a position of type e. In a similar way, I will assume that quanto is a semantically vacuous element which is base-generated in Spec of a (gradable) adjective/adverb phrase. However, unlike for Heim and Kratzer's vacuous pronoun, where the movement is covert, I will assume that in the case of quanto the movement occurs overtly to the $\mathrm{CP}$ of the comparative clause. At LF, quanto yields a $\lambda$-abstraction over a position of type $\mathbf{d}$ (degree). ${ }^{16}$ The interpretation of the main clause as a set of degrees will come about at LF by raising the generalized quantifier expression [più $\varphi$ ] from a DegP position inside the matrix adjective/adverb phrase. In a type-theoretical framework with $\mathbf{d}$ as the type of degrees, the comparative marker più is interpreted as a function of type $<<\mathbf{d}, \mathbf{t}>,<<\mathbf{d}, \mathbf{t}>, \mathbf{t}>>$, whereas the comparative introducer quanto gets the basic type d. The lexical entry for più that I assume is the following (this entry is based on Seuren's (1973) semantic analysis of comparatives):

$$
\llbracket \text { più } \rrbracket=\lambda P_{<\mathrm{d}, \mathrm{t}>} \cdot \lambda Q<\mathrm{d}, \mathrm{t}>\cdot \exists d[\neg P(d) \wedge \mathrm{Q}(d)]
$$

As for the gradable adverb presto, I will assume that it is construed at LF as a predicate of eventualities (with a slot for a degree argument, of course). ${ }^{17}$ Taking $\mathbf{E}$ to be the basic type of eventualities, presto will denote a function of type $<\mathbf{d},<\mathbf{E}, \mathbf{t}>>$, as specified by the following clause:

\footnotetext{
${ }^{16}$ I thank an anonymous reviewer for suggesting this line of analysis for the wh-word quanto.

17 I follow Parsons (1985) in using the word 'eventuality' as a cover term which stands for states, activities, and events proper.
} 


$$
\llbracket \text { presto }=\lambda d_{\mathrm{d}} \cdot \lambda e_{\mathrm{E}} \cdot \operatorname{presto}^{\prime}(e, d)
$$

Moreover, I will assume the following:

- Degrees in the set $\mathrm{DEG}_{\text {presto }}$ are time instants, i.e. $\mathrm{DEG}_{\text {presto }}=\mathrm{T}$, where time instants in their role as presto-degrees are ordered by the usual relation of temporal precedence $\leq_{\mathrm{T}}$, which is a linear order; ${ }^{18}$

- The meaning of a predicative formula like 'presto' $(e, d)$ ' is fixed by the following equivalence:

$$
\text { (Equil) } \operatorname{presto}^{\prime}(e, d) \equiv \tau(\gamma(e)) \leq_{\mathrm{T}} d
$$

where $\tau$ is the temporal trace function, and $\gamma$ is the function mapping any eventuality onto its instantaneous final part ( $\gamma$ reduces to the identity function for those eventualities which are already instantaneous, while it yields the culmination for events such as proving a theorem).

From the equivalence (Equi) in (a4) above, which I repeat below, and (Equi1), we obtain (Equi2), by transitivity and symmetry of ' $\equiv$ ':

$$
\begin{aligned}
& \text { (Equi) } P(x, d) \equiv f_{P}(x) \geq_{P} d \\
& \text { (Equi2) } f_{\text {presto }}(e) \geq_{\text {presto }} d \equiv \tau(\gamma(e)) \leq_{\mathrm{T}} d
\end{aligned}
$$

The equivalence (Equi2) is important because it allows us to establish two points about the semantics of presto:

(a) It enables us to define the measure function $f_{\text {presto }}$ as the composition of $\tau$ and $\gamma$ (the result of applying the measure function $f_{\text {presto }}$ to the eventuality $e$ is just the temporal trace of the instantaneous final part of $e$ );

(b) It allows us to regard the relation being greater than or equal to restricted to the set $\mathrm{DEG}_{\text {presto }}$ as being the same as the relation precedes or coincides with defined over time instants.

Points (a) and (b) contain the ingredients one needs for translating the comparative analysis with quantification over degrees into a temporal analysis with quantification over times. I will now give an example of such a translation.

\footnotetext{
${ }_{18}$ In assuming that degrees in the set $\mathrm{DEG}_{\text {presto }}$ are time instants, I follow von Stechow (2006) and Bonomi (2005). von Stechow (2006) also assumes that time instants are linearly ordered, as I do here, whereas Bonomi (2005) assumes that the temporal order is a tree-like relation.
} 
The general framework which I presuppose is standard in event semantics: verb predicates, as well as adverbial modifiers, project at LF an argument position for eventualities, which is abstracted over by the $\lambda$-operator. Adverbial modification is handled by means of predicate intersection, that is to say, the $\lambda$-abstracts $\lambda e_{\mathrm{E}} \cdot \mathrm{V}(\ldots e \ldots)$ and $\lambda e_{\mathrm{E}} \cdot \operatorname{Adv}(\ldots e \ldots)$, which correspond to the verbal and to the adverbial projection, respectively, are combined so as to yield the derived abstract $\lambda e_{\mathrm{E}} \cdot[\mathrm{V}(\ldots e \ldots) \wedge \operatorname{Adv}(\ldots e \ldots)]$. A default operation of existential closure maps a $\lambda$-abstract $\lambda e_{\mathrm{E}} \cdot \varphi(e)$ onto the existentially quantified formula $\exists e \varphi(e)$. I will further assume a variant of the referential approach to tense, in which each tense bears a referential index at LF and introduces an interval variable bearing the same index in the semantic representation of a tensed sentence. The semantic value of a tense $\mathrm{Tns}_{j}$ is of type $<\mathbf{E}, \mathbf{t}>$. In what follows, we will be concerned only with the analysis of past tense sentences; a tense Past ${ }_{j}$ will be interpreted as the function $\lambda e_{\mathrm{E}} \cdot \tau(e) \subseteq \mathrm{i}_{j}$, where $\mathrm{i}_{j}$ is the time interval contributed by Past ${ }_{j}$ itself (and is presupposed to precede the utterance moment on the time line), $\tau$ is the temporal trace function, taking any eventuality $e$ onto the time interval representing the temporal extension of $e$, and $\subseteq$ is the relation of inclusion between time intervals; the semantic value of $\mathrm{Tns}_{j} \mathrm{combines}$ with a $\lambda$-abstract $\lambda e_{\mathrm{E}} \cdot \mathrm{V}(e)$ (corresponding to the verb predicate to which the tense refers) via predicate intersection, yielding the derived abstract $\lambda e_{\mathrm{E}} \cdot[\tau(e) \subseteq$ $\left.\mathrm{i}_{j} \wedge \mathrm{V}(e)\right]$.

In this framework, sentence (30) gets the LF-representation (31), which is interpreted as formula (32):

Lea arrivò presto.

'Lea arrived early.'

$$
\begin{aligned}
& \exists\left[\left[\operatorname{Past}_{1}[\lambda e \cdot \operatorname{arrivare}(\text { Lea, } e)]\right]\left[\lambda e \cdot \operatorname{presto}^{\prime}(e, d)\right]\right] \\
& \exists e\left[\tau(e) \subseteq \mathrm{i}_{1} \wedge \operatorname{arrivare}(\text { Lea, } e) \wedge \operatorname{presto}^{\prime}(e, d)\right]
\end{aligned}
$$

Formula (32) says that there exists an event whose temporal trace is included in the past interval $i_{1}$, which is an event of Lea's arrival that occurs early to degree $d$.

The main assumptions concerning the surface syntax and the LF-syntax of clausal comparatives are illustrated by means of the following example:

$$
\begin{aligned}
& \text { Gianni è più alto di quanto } \\
& \text { Gianni is more tall of how-much sia } \\
& \text { 'Gianni is taller than Piero is tall.' }
\end{aligned}
$$

The phrase marker for the S-structure of (33) is given below as (33-S). 
$(33-S)$

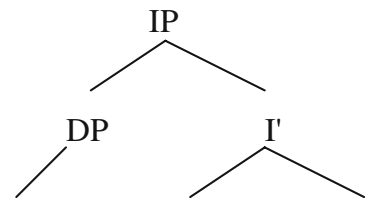

\section{Gianni}
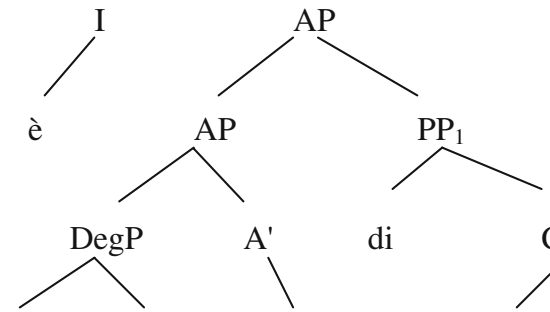

di

più

$t_{1}$<smiles>C[Te]</smiles>

quanto 2<smiles>C[Te]C</smiles>

IP

alto
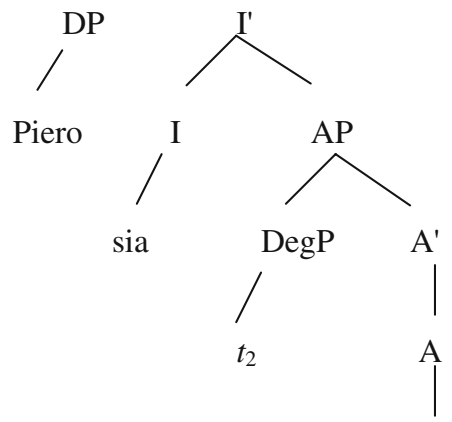

alto

In (33-S) the trace $t_{2}$ is in the position from which quanto has been moved, and the trace $t_{1}$ is in the position from which $\mathrm{PP}_{1}$ has been moved. ${ }^{19}$ To derive (33)'s $\mathrm{LF}, \mathrm{PP}_{1}$ moves back to the position which is filled by $t_{1}$ at $\mathrm{S}$-structure. After this

${ }^{19}$ I follow Bresnan (1973) in assuming that the second term of comparison (a than-phrase in English; a di quanto-/che-phrase in Italian) is base-generated as sister to the comparative morpheme -er/più, and then extraposed at S-structure. The extraposed phrase is then reconstructed in the position from which it originates in order for the comparative sentence to be semantically interpreted. 
reconstruction has taken place, $\mathrm{QR}$ applies to the highest $\mathrm{DegP}$ and adjoins it to the root IP, giving rise to the LF-structure (33-LF) below. ${ }^{20}$

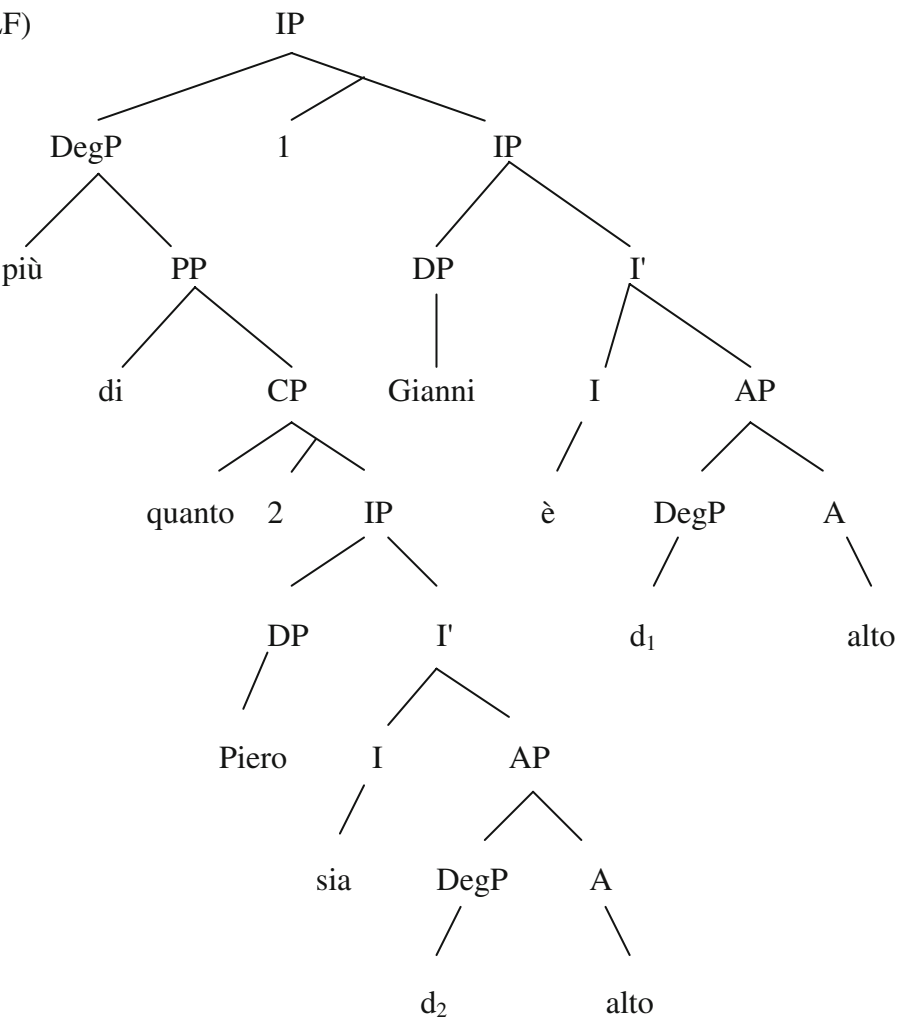

Let me illustrate how the above assumptions interact, by working out the analysis of a sample sentence with prima. Consider (34):

(34) Gianni arrivò prima che arrivasse Lea.

'Gianni arrived before Lea arrived.'

The main claim of my analysis is that prima has a comparative nature. More exactly, I will assume that prima is a synthetic comparative form, like English earlier. This means that at S-structure the Spec position of the AdvP headed by prima has an empty DegP node and, as in other comparative structures, the second term of comparison (realized in (34) as a che-phrase) is base-generated as a sister of the empty comparative element in DegP and then extraposed. The S-structure of (34) is (34-S):

\footnotetext{
${ }^{20}$ I assume that at LF the traces are of the appropriate semantic type required by the predicate they combine with. 
$(34-S)$

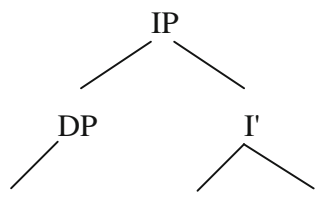

Gianni

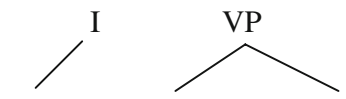

arrivò
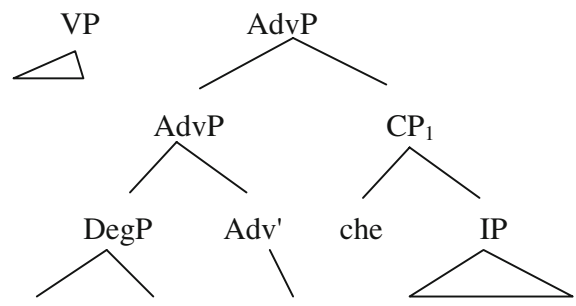

$t_{1} \quad \operatorname{Adv} \quad$ arrivasse Lea
।
prima

In the course of the derivation from S-structure to LF, prima is decomposed into the two elements più and presto: più (like -er of English synthetic comparatives) is moved into the empty node in DegP, while presto remains in Adv, as the underlying lexical head of the comparative construction. The lexical decomposition of prima into più and presto is shown in the intermediate structure $\left(34_{1}\right)$.

$\left(34_{1}\right)$
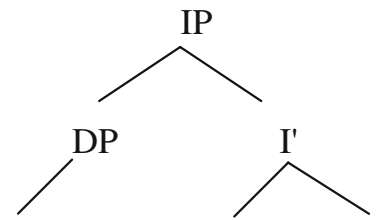

Gianni
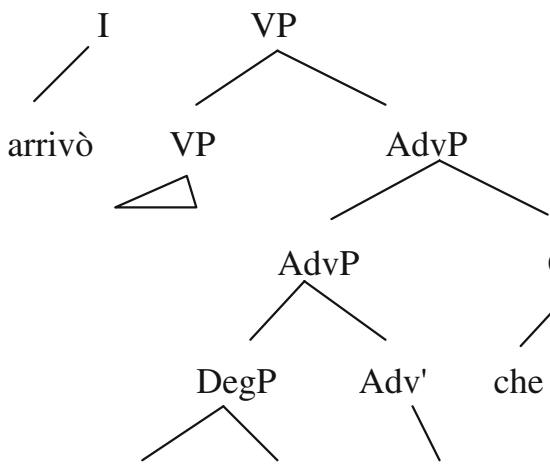

più

$t_{1}$

Adv
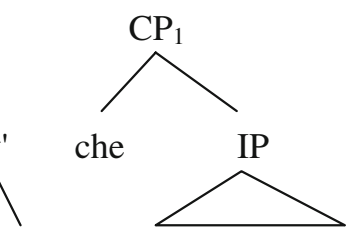

arrivasse Lea

$$
\text { presto }
$$


In comparative sentences like Gianni is taller than Piero is it is usually assumed that the predicate tall has been deleted from the comparative clause and that it is reconstructed at LF. I will assume that this also happens with the complement of più presto: the predicate presto has been deleted and is reconstructed at LF (the reconstructed element will be an AdvP headed by presto, with an empty DegP node in Spec). Reconstruction of presto yields the intermediate structure $\left(34_{2}\right)$ :

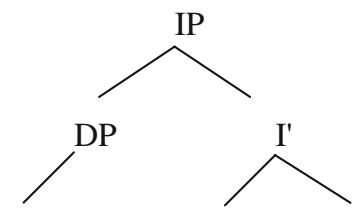

Gianni

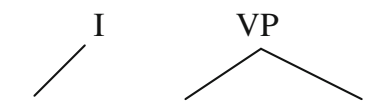

arrivò
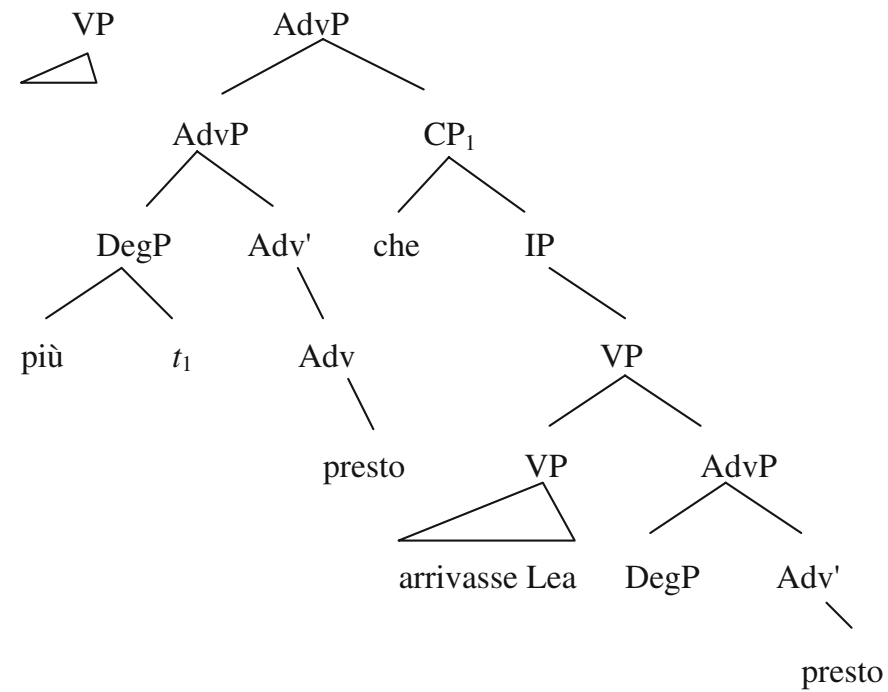

In $\left(34_{2}\right)$ we still do not have a type $<\mathbf{d}, \mathbf{t}>$ denotation for $\mathrm{CP}_{1}$ that we can use to feed the function denoted by più. I will assume that the lower DegP position in $\left(34_{2}\right)$ is occupied by a phonologically empty pronoun of type d, which undergoes QR and is adjoined to the lower IP, giving rise to $\lambda$-abstraction over a type d position. This assumption guarantees that we get the desired $<\mathbf{d}, \mathbf{t}>$ denotation for $\mathrm{CP}_{1}$, letting us derive the structure $\left(34_{3}\right)$ for $\mathrm{CP}_{1}$ : 
$\left(34_{3}\right)$

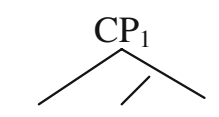

che 2 IP
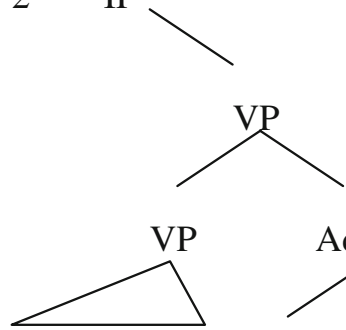

AdvP

arrivasse Lea

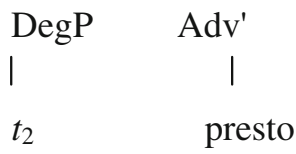

By moving $\mathrm{CP}_{1}$ back to its base position, we further obtain $\left(34_{4}\right)$ :

$(344)$
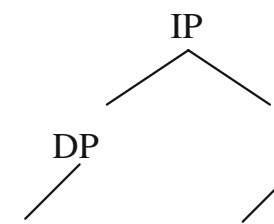

Gianni
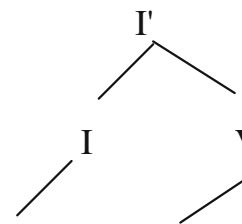

arrivò
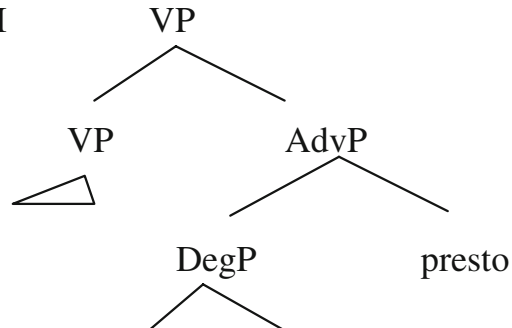

più

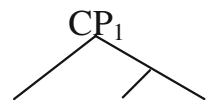

che 2 IP
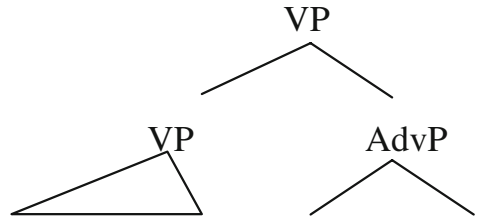

arrivasse Lea

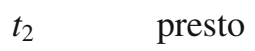


The highest DegP (a generalized quantifier over degrees) is then QR-ed and adjoined to the matrix IP, leaving a coindexed trace behind. This movement yields $\left(34_{5}\right)$ :

$\left(34_{5}\right) \quad$ [IP [DegP più che 2 arrivasse Lea $t_{2}$ presto $_{5}$ [IP 5 Gianni arrivò [AdvP $t_{5}$ presto]]]

By existentially closing the event arguments of the predicates, we get the final LF-structure (34-LF).

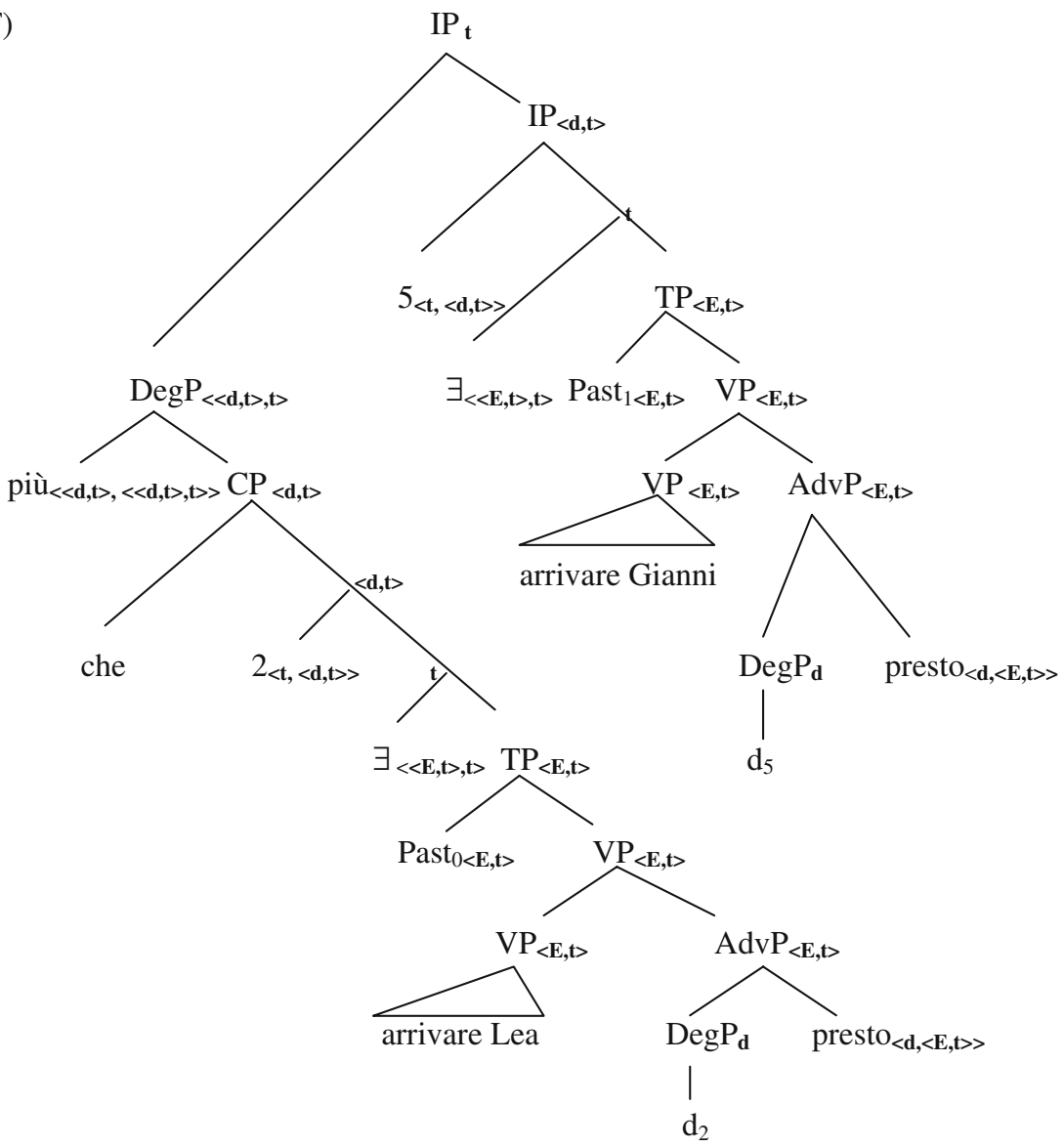

The main ingredients of the compositional interpretation of (34-LF) are the semantic values of the comparative determiner più and its two arguments, given in (a)-(c) below.

(a) $\llbracket$ più $\rrbracket=\lambda P_{<\mathrm{d}, \mathrm{t}>} \cdot \lambda Q_{<\mathrm{d}, \mathrm{t}>} \cdot \exists d[\neg P(d) \wedge Q(d)]$ 
(b) $\llbracket$ che $2 \exists\left[\left[\right.\right.$ Past $_{0}[$ arrivare Lea $\left.]\right]\left[\mathrm{d}_{2}\right.$ presto $\left.]\right] \rrbracket=\lambda d_{2} \cdot \exists e_{3}\left[\tau\left(e_{3}\right) \subseteq \mathrm{i}_{0} \wedge\right.$ $\operatorname{arrivare}\left(\right.$ Lea, $\left.\left.e_{3}\right) \wedge \operatorname{presto}^{\prime}\left(e_{3}, d_{2}\right)\right]$

(c) $\llbracket 5 \exists\left[\left[\right.\right.$ Past $_{1}[$ arrivare Gianni $\left.]\right]\left[\mathrm{d}_{5}\right.$ presto $\left.]\right] \rrbracket=\lambda d_{5} \cdot \exists e_{4}\left[\tau\left(e_{4}\right) \subseteq \mathrm{i}_{1} \wedge\right.$ $\operatorname{arrivare}\left(\right.$ Gianni, $\left.\left.e_{4}\right) \wedge \operatorname{presto}^{\prime}\left(e_{4}, d_{5}\right)\right]$

By applying functional application twice, we get the following truth conditions:

$$
\begin{aligned}
\llbracket(34-\mathrm{LF}) \rrbracket=1 \quad \text { iff } \quad & \exists d\left[\neg \exists e_{3}\left[\tau\left(e_{3}\right) \subseteq \mathrm{i}_{0} \wedge \operatorname{arrivare}\left(\operatorname{Lea}, e_{3}\right) \wedge \operatorname{presto}^{\prime}\left(e_{3}, d\right)\right]\right. \\
& \left.\wedge \exists e_{4}\left[\tau\left(e_{4}\right) \subseteq \mathrm{i}_{1} \wedge \text { arrivare }\left(\operatorname{Gianni}, e_{4}\right) \wedge \operatorname{presto}^{\prime}\left(e_{4}, d\right)\right]\right]
\end{aligned}
$$

In my analysis the existential closure of the event variable corresponding to the prima-clause takes scope under negation. In this, I follow the standard practice of letting negation take scope over the event quantifier (see Parsons 1990). According to my analysis, for (34) to be true there must be a degree of earliness $d$ such that a past event of Gianni's arriving is early to $d$, whereas no past event of Lea's arriving is early to $d$. Let's suppose that in the relevant domain there are an event $e$ of Gianni's arriving which occurs at 3:00 pm and an event $e^{\prime}$ of Lea's arriving which occurs at 3:05 pm. It follows that there is a degree $d$ in relation to which the event $e$ is early, whereas the event $e^{\prime}$ is not: for example, 3:00 pm. The choice $d=3: 00 \mathrm{pm}$ is easily shown to be adequate, since it is true of the temporal trace of $e$ that it either precedes or coincides with 3:00 pm, whereas the same is not true of the temporal trace of $e^{\prime}$.

The semantic analysis of (34) I proposed can be straightforwardly translated into a temporal analysis with quantification over times. The interpretation we have obtained for (34), repeated below as (35), is equivalent to (36) ${ }^{21}$ By the instantaneous character of arrival events, (36) further reduces to (37).

$$
\begin{aligned}
& \exists d\left[\neg \exists e_{3}\left[\tau\left(e_{3}\right) \subseteq \mathrm{i}_{0} \wedge \operatorname{arrivare}\left(\text { Lea, } e_{3}\right) \wedge \operatorname{presto}^{\prime}\left(e_{3}, d\right)\right] \wedge\right. \\
& \left.\exists e_{4}\left[\tau\left(e_{4}\right) \subseteq \mathrm{i}_{1} \wedge \operatorname{arrivare}\left(\text { Gianni, } e_{4}\right) \wedge \text { presto }\left(e_{4}, d\right)\right]\right] \\
& \exists d\left[\neg \exists e\left[\operatorname{arrivare}(\text { Lea, } e) \wedge \tau(\gamma(e)) \leq_{\mathrm{T}} d\right] \wedge \exists e[\text { arrivare }(\text { Gianni, } e) \wedge\right. \\
& \left.\left.\tau(\gamma(e)) \leq_{\mathrm{T}} d\right]\right] \\
& \exists t\left[\neg \exists e\left[\operatorname{arrivare}(\text { Lea, } e) \wedge \tau(e) \leq_{\mathrm{T}} t\right] \wedge \exists e[\operatorname{arrivare}(\text { Gianni, } e) \wedge\right. \\
& \left.\left.\tau(e) \leq_{\mathrm{T}} t\right]\right]
\end{aligned}
$$

Formula (37) entails that there exists a time $t$ such that an event of Gianni's arriving occurs at $t$, and no event of Lea's arriving has occurred yet at $t$. This is as it should be.

${ }^{21}$ This holds by (Equi1).

(Equil) $\operatorname{presto}^{\prime}(e, d) \equiv \tau(\gamma(e)) \leq{ }_{\mathrm{T}} d$ 
Let's see which predictions this analysis makes when the argument clause of prima contains a stative predicate. I make the standard assumption that stative predicates are homogeneous, i.e. they satisfy the following condition: ${ }^{22}$

$$
(\mathrm{HOM}) \quad \forall e\left[\mathrm{P}(e) \rightarrow \forall e^{\prime}\left[e^{\prime} \subseteq_{\mathrm{E}} e \rightarrow \mathrm{P}\left(e^{\prime}\right)\right]\right]
$$

Consider now sentence (38), along with its semantic representation (39):

(38) Gianni era ammalato prima che lo fosse Lea.

'Gianni was sick before Lea was sick.'

$\exists d\left[\neg \exists e_{3}\left[\operatorname{Past}_{0}\left(e_{3}\right) \wedge\right.\right.$ essere-ammalata(Lea, $\left.\left.e_{3}\right) \wedge \operatorname{presto}^{\prime}\left(e_{3}, d\right)\right] \wedge$ $\exists e_{4}\left[\operatorname{Past}_{1}\left(e_{4}\right) \wedge\right.$ essere-ammalato(Gianni, $\left.\left.\left.e_{4}\right) \wedge \operatorname{presto}^{\prime}\left(e_{4}, d\right)\right]\right]$

By (Equi1), (39) reduces to (40):

(40) $\exists d\left[\neg \exists e_{3}\left[\operatorname{Past}_{0}\left(e_{3}\right) \wedge\right.\right.$ essere-ammalata(Lea, $\left.\left.e_{3}\right) \wedge \tau\left(\gamma\left(e_{3}\right)\right) \leq_{\mathrm{T}} d\right] \wedge$ $\exists e_{4}\left[\operatorname{Past}_{1}\left(e_{4}\right) \wedge\right.$ essere-ammalato(Gianni, $\left.\left.\left.e_{4}\right) \wedge \tau\left(\gamma\left(e_{4}\right)\right) \leq_{\mathrm{T}} d\right]\right]$

By homogeneity of the stative predicate essere ammalato ('to be sick'), we can already instantiate the quantified variables $e_{3}$ and $e_{4}$ to instantaneous events, that is, $\gamma\left(e_{3}\right)=e_{3}$ and $\gamma\left(e_{4}\right)=\mathrm{e}_{4}$. Hence, (40) can be reduced to (41):

$$
\begin{aligned}
& \exists t\left[\neg \exists e_{3}\left[\operatorname{Past}_{0}\left(e_{3}\right) \wedge \text { essere-ammalata }\left(\text { Lea }, e_{3}\right) \wedge \tau\left(e_{3}\right) \leq_{\mathrm{T}} t\right)\right] \wedge \\
& \left.\exists e_{4}\left[\operatorname{Past}_{1}\left(e_{4}\right) \wedge \text { essere-ammalato }\left(\text { Gianni, } e_{4}\right) \wedge \tau\left(e_{4}\right) \leq_{\mathrm{T}} t\right]\right]
\end{aligned}
$$

Formula (41) correctly predicts that sentence (38) is true just in case there is a time $t$ such that Gianni was sick at $t$ and Lea was not yet sick at $t$.

The comparative analysis of prima thus predicts that a sentence 'A prima che B' with stative clauses A and B will be interpreted as the temporal quantification: There is a time at which $A$ that precedes every time at which $B$. This quantification coincides with what is assumed by several analyses of before proposed in the literature: ${ }^{23}$

$$
\text { A before } \mathrm{B} \Rightarrow \exists t_{0}\left[\mathrm{~A}^{\prime}\left(t_{0}\right) \wedge \forall t_{1}\left[\mathrm{~B}^{\prime}\left(t_{1}\right) \rightarrow t_{0}<t_{1}\right]\right]
$$

To my knowledge, none of the authors who have endorsed this kind of analysis have ever provided a compositional motivation for the presence of the universal quantifier in the logical representation of before. This quantifier is always postulated for the need of explaining the logical, polarity, and veridicality

\footnotetext{
${ }^{22}$ The symbol ' $\subseteq$ ' denotes the part-of relation between eventualities.

${ }^{23}$ See Higginbotham (1988), Landman (1991), Valencia et al. (1994), Ogihara (1995), among others, for proposals along these lines.
} 
properties of before. Interestingly, the comparative analysis of prima can predict the "universal force" of this connective, and enables one to avoid the ad hoc postulation of a universal quantifier in the logical representation of prima-sentences. $^{24}$

A point that must be mentioned before developing the analysis of dopo is related to the non-veridicality of prima. This property can be defined as follows.

\section{Non-veridicality of prima}

There is no valid inference from the truth of a sentence A prima che/di B to the truth of its temporal clause $\mathbf{B}$.

Non-veridicality is attested, for example, by (42), which is given along with its semantic representation.

$$
\begin{array}{llll}
\text { La bomba esplose prima che colpisse il bersaglio. } & \text { il } \\
\text { the bomb exploded before that hit( } 3 \mathrm{sg} \text {, subj) the target }
\end{array}
$$

'The bomb exploded before it hit the target.'

$\exists d\left[\neg \exists e_{3}\left[\operatorname{Past}_{0}\left(e_{3}\right) \wedge\right.\right.$ hit(the-bomb, the-target, $\left.e_{3}\right) \wedge$ presto' $\left.\left(e_{3}, d\right)\right] \wedge$ $\exists e_{4}\left[\operatorname{Past}_{1}\left(e_{4}\right) \wedge\right.$ explode(the-bomb, $\left.\left.\left.e_{4}\right) \wedge \operatorname{presto}^{\prime}\left(e_{4}, d\right)\right]\right]$

From (42), one cannot validly infer that the bomb hit the target. Sentence (42) rather seems to legitimate an inference to the negation of its prima-clause, as it suggests that the bomb did not hit the target. By looking at the logical representation of the sentence, one can see that (42) is correctly predicted by my analysis not to entail its prima-clause. The formula representing (42)'s truth conditions says that there is a time (degree) $t$ such that a past event of explosion

\footnotetext{
${ }^{24}$ My claim that no compositional motivation is provided in the literature for the universal quantifier underlying before needs to be qualified. Beaver and Condoravdi (2003) provide a compositional analysis of before which explains the apparent universal force of before as an epiphenomenon of the actual semantic representation of 'A before B', which they assume to be as follows (see B\&C 2003, Sect. 6):

'A before $\mathrm{B}$ ' is true in $w_{0}$ iff $\exists t\left[A\left(<w_{0}, t>\right) \wedge t<\right.$ earliest $\left._{\text {alt }(w o, t)}(B)\right]$

Although the semantic clause for before contains no overt universal quantifier, the universal force of before is derived by exploiting the fact that in order for a time $\mathrm{t}$ to precede the earliest $B$-time, t must precede every $B$-time. So, my claim only holds for those analyses, like Higginbotham's, Landman's, Valencia et al.'s, and Ogihara's, that introduce an overt universal quantifier in the semantic clause for before. Notice, by the way, that Beaver and Condoravdi correctly predict that after should not have this kind of universal force, as originally pointed out in Anscombe (1964). Indeed, although their analysis for after mirrors the one they assume for before, following the earliest $B$-time only entails following some $B$-time:
}

'A after $\mathrm{B}$ ' is true in $w_{0}$ iff $\exists t\left[A\left(<w_{0}, t>\right) \wedge t>\right.$ earliest $\left._{\text {alt }(w o, t)}(B)\right]$ 
of the bomb has occurred at $t$, whereas no past event of the bomb hitting the target has yet occurred at $t$. These truth conditions clearly do not entail that the bomb has ever hit the target. Indeed, if existential closure of the event variable corresponding to the prima-clause always takes scope under the negation introduced by the comparative marker più, this fact will rule out any inference to the truth of the temporal clause as invalid.

\subsection{Semantic analysis of dopo}

The semantic analysis of dopo which I propose is based on claim (C2), repeated here:

(C2) Dopo is not a temporal comparative, it is a temporal preposition contributing a binary relation over events.

Dopo is characterized as an "atomic" predicate, i.e. it has no internal structure. In the case of prima, I suggested an analysis by which prima is decomposed at LF by means of the comparative più presto ('earlier'). No similar decomposition is proposed for dopo in terms of più tardi ('later').

The basic meaning of dopo is specified by its semantic clause as a function of type $<\mathbf{E},<\mathbf{E}, \mathbf{t}>>$, i.e. a binary relation over events.

$$
\llbracket \mathrm{dopo} \rrbracket=\lambda e_{2} \cdot \lambda e_{1} \cdot \tau\left(e_{1}\right)>\tau\left(e_{2}\right)
$$

This makes it clear that no semantic structure of quantifiers and/or connectives is contributed by 'dopo' per se. However, the above lexical entry can be directly applied only to the analysis of simple copular sentences such as La tempesta fu dopo la mezzanotte ('The storm was after midnight'), in which the arguments of the connective are analyzable as event-referring expressions. If we want to give a compositional analysis of more complex sentences, we have to revise the basic lexical entry so as to allow for type $<\mathbf{E}, \mathbf{t}>$ arguments, i.e. clausal arguments. I propose a derived lexical entry which specifies a type $<<\mathbf{E}, \mathbf{t}>,<<\mathbf{E}, \mathbf{t}>,<\mathbf{E},<\mathbf{E}, \mathbf{t}>>>>$ denotation, i.e. a function which yields a binary relation over events by taking two type $<\mathbf{E}, \mathbf{t}>$ arguments. The derived clause is the following:

$$
\llbracket \mathrm{dopo} \rrbracket=\lambda P \cdot \lambda Q \cdot \lambda e_{2} \cdot \lambda e_{1} \cdot P\left(e_{2}\right) \wedge Q\left(e_{1}\right) \wedge \tau\left(e_{1}\right)>\tau\left(e_{2}\right)
$$

The main assumptions concerning the surface syntax and the LF-syntax of dopo-sentences are illustrated by the following example:

(43) Lea è arrivata dopo che è arrivato Gianni.

'Lea arrived after Gianni arrived.'

I give a representation of the surface structure of (43) in (43-S), while the corresponding LF-representation is given in (43-LF). 
$(43-S)$

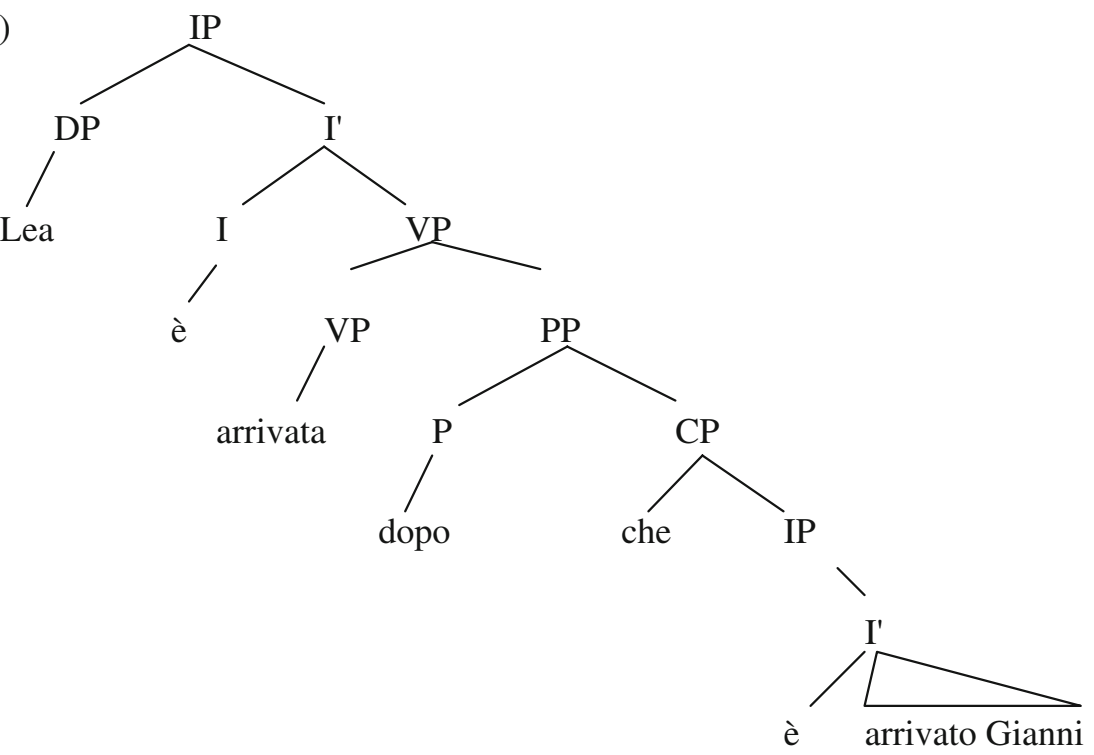

(43-LF)

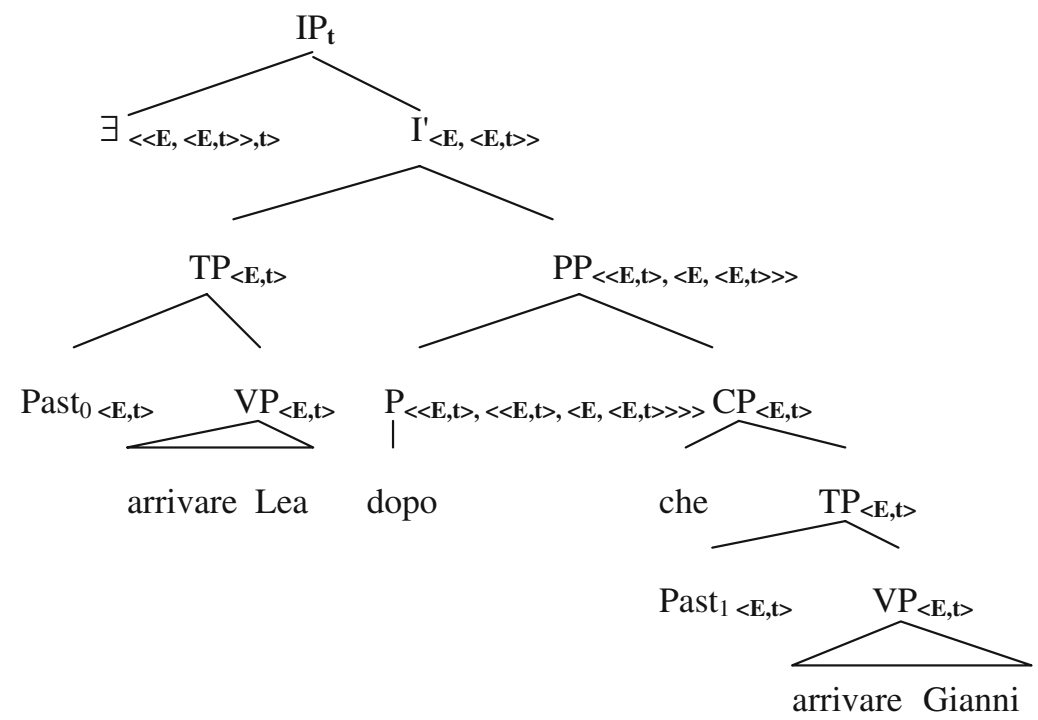

The LF-representation makes it clear that, unlike what happens in the analysis of prima-sentences, no covert movement applies to any constituent of doposentences. The logical formula which represents the semantic interpretation of (43-LF) is the following ${ }^{25}$ :

\footnotetext{
25 In analyzing sentence (43), I make the simplifying assumption that the matrix clause and the subordinate clause are both past-tensed, even though they are present perfect clauses.
} 


$$
\begin{aligned}
& \exists e_{3} \exists e_{4}\left[\operatorname{Past}_{1}\left(e_{3}\right) \wedge \operatorname{arrivare}\left(\text { Gianni, } e_{3}\right) \wedge \operatorname{Past}_{0}\left(e_{4}\right) \wedge \operatorname{arrivare}\left(\text { Lea, } e_{4}\right)\right. \\
& \left.\wedge \tau\left(e_{4}\right)>\tau\left(e_{3}\right)\right]
\end{aligned}
$$

This formula says that there is a past event of Lea's arrival and a past event of Gianni's arrival such that the temporal trace of the former follows the temporal trace of the latter. This is indeed the intuitive meaning of sentence (43). The semantic derivation which takes from (43-LF) to its semantic interpretation $\left(43^{\prime}\right)$ is summarized below.

$\llbracket\left[{ }_{\mathrm{PP}}\left[\mathrm{P}\right.\right.$ dopo] $\left[{ }_{\mathrm{CP}}\right.$ che Past $_{1}[$ arrivare Gianni $\left.\left.]\right]\right] \rrbracket=\llbracket d o p o \rrbracket\left(\llbracket\left[\right.\right.$ che Past $_{1}[$ arrivare Gianni $]] \|)=\left[\lambda P \cdot \lambda Q \cdot \lambda e_{3} \cdot \lambda e_{4} \cdot P\left(e_{3}\right) \wedge Q\left(e_{4}\right) \wedge \tau\left(e_{4}\right)>\tau\left(e_{3}\right)\right]\left(\lambda e_{3} \cdot \mathrm{Past}_{1}\left(e_{3}\right) \wedge\right.$ $\operatorname{arrivare}\left(\right.$ Gianni, $\left.\left.e_{3}\right)\right)=\lambda Q \cdot \lambda e_{3} \cdot \lambda e_{4} \cdot \operatorname{Past}_{1}\left(e_{3}\right) \wedge \operatorname{arrivare}\left(\right.$ Gianni, $\left.e_{3}\right) \wedge$ $Q\left(e_{4}\right) \wedge \tau\left(e_{4}\right)>\tau\left(e_{3}\right)$

$\llbracket\left[\operatorname{TP}_{\text {Past }}[\operatorname{arrivare~Lea~}]\right] \rrbracket_{\|}=\lambda e_{4} \cdot \operatorname{Past}_{0}\left(e_{4}\right) \wedge \operatorname{arrivare}\left(\mathrm{Lea}, e_{4}\right)$

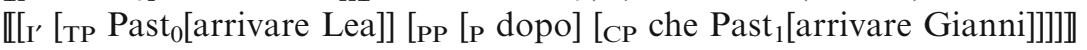

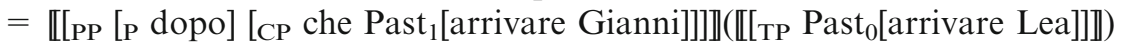

$=\left[\lambda Q \cdot \lambda e_{3} \cdot \lambda e_{4} \cdot \operatorname{Past}_{1}\left(e_{3}\right) \wedge \operatorname{arrivare}\left(G i a n n i, e_{3}\right) \wedge Q\left(e_{4}\right) \wedge \tau\left(e_{4}\right)>\tau\left(e_{3}\right)\right]$ $\left(\lambda e_{4} \cdot \operatorname{Past}_{0}\left(e_{4}\right) \wedge \operatorname{arrivare}\left(\right.\right.$ Lea, $\left.\left.e_{4}\right)\right)$

$=\lambda e_{3} \cdot \lambda e_{4} \cdot \operatorname{Past}_{1}\left(e_{3}\right) \wedge \operatorname{arrivare}\left(\right.$ Gianni, $\left.e_{3}\right) \wedge \operatorname{Past}_{0}\left(e_{4}\right) \wedge$ arrivare $\left(\right.$ Lea, $\left.e_{4}\right)$ $\wedge \tau\left(e_{4}\right)>\tau\left(e_{3}\right)$

Finally, the default operation of existential closure applies, and takes us to the closed formula which gives the interpretation (43'):

$$
\begin{aligned}
& \exists e_{3} \exists e_{4}\left[\operatorname{Past}_{1}\left(e_{3}\right) \wedge \operatorname{arrivare}\left(\text { Gianni, } e_{3}\right) \wedge \operatorname{Past}_{0}\left(e_{4}\right) \wedge \operatorname{arrivare}\left(\text { Lea, } e_{4}\right)\right. \\
& \left.\wedge \tau\left(e_{4}\right)>\tau\left(e_{3}\right)\right]
\end{aligned}
$$

4.3 Explanation of some of the previous data

\subsubsection{Distribution of the phrase di quanto}

Let's consider the pair (44a, b) (identical to the pair (1a)-(2a) from Sect. 2.1):

(44)a. Gianni arrivò prima di quanto pensavamo.

'Gianni arrived earlier than we thought.'

b. *Gianni arrivò dopo di quanto pensavamo.

In my analysis, the grammatical contrast between (44a) and (44b) is explained as follows. On the one hand, given its underlying comparativity, prima requires that its internal argument provides a set of degrees. On the other hand, the comparative introducer quanto has been assumed to be a semantically vacuous pronoun of type d, which must undergo QR for type reasons, giving rise to $\lambda$-abstraction over a degree position. This yields an expression denoting a set of degrees, the right semantic type for the comparative to combine with. Concerning (44a), a natural assumption is that quanto is generated in a position 
inside the elided clausal complement of the epistemic verb, as suggested by the following pre-ellipsis version of (44a):

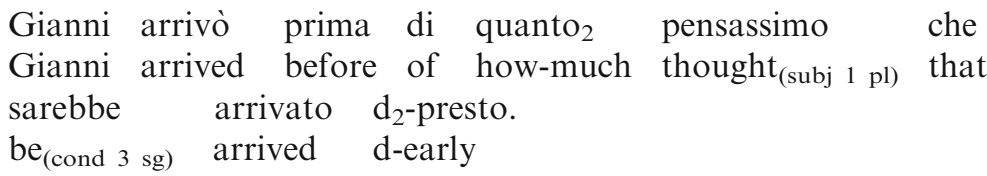

Assuming that the epistemic verb pensare ('to think') is a universal quantifier over epistemically accessible worlds, which takes scope over the negation introduced by the comparative, and introducing an extra argument slot for the world parameter, the semantic representation that we get for sentence (44a) is the following:

$$
\begin{aligned}
& \exists d\left[\forall w \left[\operatorname{Access}\left(w_{0}, w\right) \rightarrow \neg \exists e[\operatorname{arrivare}(\mathrm{Gianni}, e, w) \wedge\right.\right. \\
& \left.\left.\operatorname{presto}^{\prime}(e, d, w)\right] \wedge \exists e\left[\operatorname{arrivare}\left(\operatorname{Gianni}, e, w_{0}\right) \wedge \operatorname{presto}^{\prime}\left(e, d, w_{0}\right)\right]\right]
\end{aligned}
$$

What this formula means is that an event of Gianni's arrival occurred with a certain degree of earliness, and no epistemic alternative is such that an event of Gianni's arrival occurred there with the same degree of earliness. Given the analysis I assume for the verb pensare, this amounts to saying that an event of Gianni's arrival occurred with a certain degree of earliness, whereas we had not thought that an event of Gianni's arrival would have occurred with such a degree of earliness. This seems to convey the meaning of (44a) correctly.

The wide scope construal of quantificational expressions occurring within comparative clauses is a phenomenon that one observes with nominal quantifiers too. For instance, sentence (47) below is interpreted with the universal quantifier scoping over the negation introduced by the comparative, as shown in (48):

Gianni arrivò prima di tutti gli altri. Gianni arrived before of all the others

'Gianni arrived before everyone else.'

$$
\begin{aligned}
& \exists d\left[\forall y\left[y \neq \text { Gianni } \rightarrow \neg \exists e\left[\operatorname{arrivare}(y, e) \wedge \operatorname{presto}^{\prime}(e, d)\right]\right]\right. \\
& \wedge \exists e[\operatorname{arrivare}(\text { Gianni, } e) \wedge \operatorname{presto}(e, d)]]
\end{aligned}
$$

I will not have anything more to say concerning the interpretation of quantifying expressions in the scope of comparatives, since this is a very general issue which does not bear directly on the main point of my discussion. What is important here is that the comparative analysis of prima, supplemented with the assumption of a wide scope construal for embedded quantifiers, can predict the semantic well-formedness and the actual reading of sentence (44a).

The analysis also predicts the unacceptability of sentence (44b), as a case of semantic ill-formedness. 
(44)b. *Gianni arrivò dopo di quanto pensavamo.

This prediction comes about by the above assumptions concerning the semantic interpretation of di quanto complements, and by the lexical entry of dopo. According to my analysis, dopo selects for an eventuality as its internal argument, whereas a di quanto complement can only provide a set of degrees as value. Therefore, the anomaly of (44b) turns out to be an instance of type mismatch.

\subsubsection{Superlative readings of constructions with the modal possibile}

What we have to explain now is the grammatical contrast illustrated by the pair $(5 \mathrm{a}, \mathrm{b})$ from Sect. 2.2, which I repeat in (49):

(49)a.

Leo è tornato il prima possibile.
Leo is returned(past participle) the before possible
'Leo came back at the earliest possible moment.'

b. *Leo è tornato il dopo possibile.

Leo is returned(past participle) the after possible

First, I have to introduce a digression concerning comparative and superlative expressions. In English there is an expression, more, which is used to form comparatives, and a different expression, most, which is used to form superlatives. In Italian, superlative and comparative meanings are conveyed by the same morphological expression, namely più. This expression occurs both in comparatives and in superlatives, as in Gianni è più intelligente di Piero ('Gianni is more intelligent than Piero') and Gianni è il più intelligente ('Gianni is the most intelligent'). I assume here that, underlyingly, più has two different meanings: one corresponds to the comparative expression more, and the other corresponds to the superlative expression most. Once we make this assumption, it is clear that we have to make a similar assumption concerning synthetic comparatives in Italian. For example, the synthetic comparative peggiore ('worse'), which occurs in comparative sentences like Gianni è peggiore di Piero ('Gianni is worse than Piero'), can also occur with superlative meaning, as in Gianni è il peggiore ('Gianni is the worst'). It is a general fact about Italian synthetic comparatives that they also have a superlative meaning. Thus, I will assume that synthetic comparatives, like più, have two different meanings, a comparative one and a superlative one.

If this picture of the behaviour of synthetic comparatives in Italian is correct, then a consequence follows regarding prima, according to our analysis. Since we assume that prima is indeed a synthetic comparative, namely that its meaning is underlyingly represented as the comparative più presto, it is thus natural to suppose that, as with other synthetic comparatives, the grammar also makes a superlative reading available for it. 
Let's now come back to the contrast between (49a) and (49b). My claim is that (49a) is a case of superlative interpretation of the synthetic expression prima; more specifically, I assume that the item più underlying prima in (49a) is the superlative più, corresponding to the English expression most, and I will write più $_{S}$ to refer to it. The semantic analysis of definite superlatives that I propose is based on Heim (1999). The basic idea of this treatment is that a superlative can be paraphrased as a comparative with a universally quantified than-phrase. For instance, the superlative sentence (50a) is taken to have the same truth conditions as the comparative (50b):

(50)a. Leo è il più pigro.

'Leo is the laziest.'

b. Leo è più pigro di ogni altro.

'Leo is lazier than everyone else.'

On this treatment, più takes three arguments, i.e. an external, an internal, and a contextual argument. For example, in the case of sentence (50a) above, the external argument is Leo, the internal argument is the property denoted by pigro, and the contextual argument is some salient set of persons. If the conversation were about Leo's class, then the contextual argument of più $\grave{S}_{S}$ might be fixed as the set of Leo's classmates, and (50a) would then mean that nobody who is different from Leo and is among Leo's classmates is as lazy as Leo.

Following Heim's treatment of English superlatives, I represent the lexical entry for più $_{S}$ as follows:

\section{Lexical entry for 'più ${ }_{S}$ ' (extensional version):}

Let $x$ be an entity, $\chi$ a gradable property, and $\mathrm{C}$ a contextually salient set.

Then $\operatorname{più~}_{S}(x, \chi, \mathrm{C})=\exists d[\chi(x, d) \wedge \forall y[[y \neq x \wedge y \in \mathrm{C}] \rightarrow \chi(y, d)]]$

For an utterance of sentence (50a) in a context in which C is the set of Leo's classmates, the present analysis yields semantic representation (51a). If we assume the meaning for più $_{S}$ given above, we derive the truth conditions in (51b):

(51)a. $\operatorname{piùs}_{S}(\operatorname{Leo}, \lambda d \cdot \lambda x \cdot \operatorname{lazy}(x, d),\{x$ : classmate-of-Leo $(x)\})$

b. $\exists d[\operatorname{lazy}(\operatorname{Leo}, d) \wedge \forall y[[y \neq \operatorname{Leo} \wedge$ classmate-of-Leo $(y)] \rightarrow \neg \operatorname{lazy}(y, d)]]$

How does the present analysis extend to the case of the adverbial superlative prima? First of all, let's observe that the superlatives with prima we are interested in are modalized superlatives, due to the occurrence of the modal predicate possibile ('possible'). For example, sentence (49a) (which I repeat below) has a meaning which can be expressed by the paraphrase 'An event of Leo's return occurred at a time $t$ such that every other event of Leo's return in any alternative world compatible with Leo's physical abilities did not occur earlier than $t$ '.

(49)a. Leo è tornato il prima possibile.

'Leo came back at the earliest possible moment.' 
This paraphrase clearly expresses the modal force of (49a). Moreover, it suggests what the role of possibile is in the interpretation of the sentence: it restricts the value of the contextual argument to events which are returns by Leo in worlds compatible with Leo's physical abilities (for instance, returns by Leo which occur in worlds where Leo can fly or move at the speed of light are excluded as not relevant to the interpretation of the superlative). Sentence (49a) thus involves an implicit comparison between the actual event of Leo's return and events of Leo's return that are possible with respect to Leo's actual physical abilities.

In order to provide a semantic analysis of sentence (49a), I have to assume an intensional version of the above lexical entry for più $_{S}$, and then I have to show how the value of the contextual argument of più ${ }_{S}$ is constrained by the modal possibile in constructions of the form [il + piùs $\mathrm{X}+$ possibile].

Lexical entry for 'più ${ }_{S}$ ' (intensional version):

Let $x$ be an entity, $\chi$ the intension of a gradable predicate, $w_{0}$ a possible world, and $\mathrm{C}$ a contextually determined set of entities. Then

$$
\operatorname{pì̀~}_{S}\left(x, \chi, w_{0}, \mathrm{C}\right)=\exists d\left[\chi\left(x, d, w_{0}\right) \wedge \forall y\left[[y \neq x \wedge y \in \mathrm{C}] \rightarrow \neg \chi\left(y, d, w_{\mathrm{n}}\right)\right]\right]
$$

Here the variable $w_{\mathrm{n}}$ can be either $w_{0}$ or some other variable. The first case will occur when no modal predicate is present, as in Leo è il più pigro ('Leo is the laziest'). The second case will occur when the modal possibile is present, as in Leo è tornato il prima possibile ('Leo came back at the earliest possible moment'); in this eventuality, $w_{\mathrm{n}}$ will be bound to the quantifier introduced by the modal possibile, as is shown below.

As for the constraint on the value of the contextual argument C, I will assume the following construction-specific rule (in the statement of the rule, $\mathrm{V}$ is a tensed verb and $\mathrm{X}$ a degree predicate; $\mathrm{V}^{\prime}$ is the event predicate corresponding to the verb V):

\section{Constraint on the value of the contextual argument $C$ :}

$\left(\mathrm{R}_{\mathrm{C}}\right)$ In a sentence of the form ' $x \mathrm{~V}$ il piùs $\mathrm{X}$ possibile', the value of the contextual argument $\mathrm{C}$ is the set $\left\{e: \exists w_{1}\left[\operatorname{Access}\left(w_{0}, w_{1}, x\right) \wedge \mathrm{V}^{\prime}\left(x, e, w_{1}\right)\right]\right\}$.

We can check this rule by considering sentence $(49 \mathrm{c})$ :

(49)c. Leo è fuggito il più rapidamente
Leo is escaped the most rapidle.
'Leo escaped as rapidly as he could.'

Intuitively, $(49 \mathrm{c})$ is interpreted as saying that Leo escaped in the actual world $w_{0}$ at a speed $v$ such that in every alternative world compatible with Leo's actual physical abilities, Leo did not escape faster than $v$. According to rule $\left(\mathrm{R}_{\mathrm{C}}\right)$, the contextual argument relevant to the interpretation of (49c) is the set of escape events by Leo which occur in worlds compatible with Leo's actual physical 
abilities. The output of the rule is adequate, as we have seen that the sentence intuitively involves a comparison between the actual event of Leo's escape and all other events of Leo's escape which occur in worlds compatible with Leo's actual physical abilities.

Coming back to the analysis of (49a), the arguments of più $\grave{S}_{\text {are specified as }}$ follows:

(a) The external argument is the event introduced by the matrix verbal predicate, i.e. the event of Leo's return;

(b) The internal argument is the intension of the gradable predicate presto, i.e. $\lambda w \cdot \lambda d \cdot \lambda e \cdot \operatorname{presto}(e, d, w)$;

(c) The modal argument is the world $w_{0}$ in which the utterance takes place;

(d) The contextual argument $\mathrm{C}$ has a value which is determined according to rule $\left(\mathrm{R}_{\mathrm{C}}\right)$.

Accordingly, the semantic representation of (49a) is (52a), for which we get the truth conditions in $(52 \mathrm{~b})$ :

(52)a. $\exists e_{1}\left[\right.$ tornare $\left(\operatorname{Leo}, e_{1}, w_{0}\right) \wedge \operatorname{più~}_{\mathrm{S}}\left(e_{1}, \lambda w \cdot \lambda d \cdot \lambda e \cdot \operatorname{presto}(e, d, w)\right.$, $w_{0},\left\{e: \exists w_{1} \operatorname{Access}\left(w_{0}, w_{1}\right.\right.$, Leo $) \wedge$ tornare $\left.\left.\left.\left(\operatorname{Leo}, e, w_{1}\right)\right\}\right)\right]$

b. $\exists e_{1}\left[\operatorname{tornare}\left(\operatorname{Leo}, e_{1}, w_{0}\right) \wedge \exists d\left[\operatorname{presto}\left(e_{1}, d, w_{0}\right) \wedge \forall e_{2} \forall w_{1}\left[\left(e_{2} \neq e_{1} \wedge\right.\right.\right.\right.$ $\operatorname{Access}\left(w_{0}, w_{1}\right.$, Leo $\left.\left.\left.\left.) \wedge \operatorname{tornare}\left(\operatorname{Leo}, e_{2}, w_{1}\right)\right) \rightarrow \neg \operatorname{presto}\left(e_{2}, d, w_{1}\right)\right]\right]\right]$

Formula (52b) says that there is an actual event of return by Leo and a degree $d$ such that $e$ is early to $d$, and no other event of return by Leo in any world compatible with Leo's actual physical abilities occurs early to $d$. This gives an adequate analysis of (49a)'s intuitive meaning.

The ill-formedness of ( $49 \mathrm{~b})$ follows in this analysis from the fact that dopo is a simple binary relation, which does not encompass a structure of the form $[$ più $+\mathrm{X}]$. In order for the semantic composition to go through, the occurrence of a gradable predicate $\mathrm{X}$ and of the superlative marker più ${ }_{S}$ at LF is required. But at the LF of the definite il dopo possibile none of these items will ever feature. Hence the process of semantic composition comes here to a halt.

\subsubsection{Distribution of expletive negation}

Recall that expletive negation can occur in sentences with comparative expressions (see Sect. 3.1 above). More precisely, it is in the comparative complement that expletive negation can appear, as shown by sentence (15) in Sect. 3.1 (repeated here as (53)).

Sparerà più in alto che non pensi.
Shoot(fut, $3 \mathrm{sg}$ ) more in high that not think(subj, 2 sg)
'He will shoot higher than you think.'


I suggest that expletive negation in these sentences is licensed by the underlying comparative marker più, in a way which I explain below. Given my assumption that the comparative marker più also occurs in the underlying representation of prima-sentences, this naturally leads us to expect that expletive negation should also be licensed in prima-sentences. This is exactly what we observe (see Sect. 2.3 above). Indeed, in a sentence like (6a) (repeated below as (54)) the complement of prima contains an overt negative marker which is not interpreted as a semantic negation.

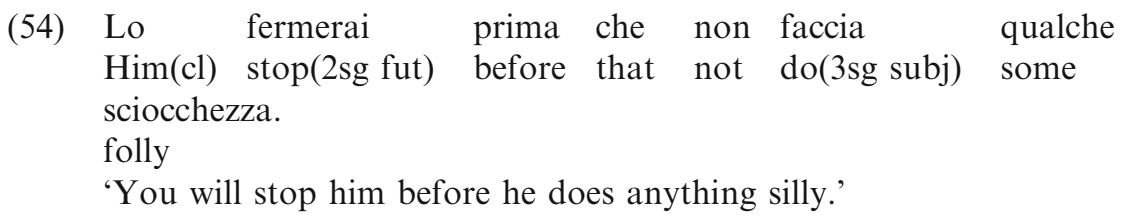

From the semantic clause for comparative più, ${ }^{26}$ we see that più introduces the negative operator $\neg$, and that the first argument of più ends up in its scope. I assume moreover that, at LF, the comparative marker più is able to absorb the negative feature of non in its C-command domain. Given that the negative feature is plausibly the only interpretable feature of the negative marker non, after this feature has been removed, nothing is left which might be relevant for the semantic interpretation, whence the semantic emptiness of non.

Since dopo lacks an underlying comparative structure, we also expect, as we observed for (6b) (repeated below as (55)), that expletive negation cannot occur in its scope:

$\begin{array}{lllll}\text { (55) }{ }^{\text {? }} \text { Lo } & \text { fermerai } & \text { dopo che non avrà } & \text { fatto } \\ \text { Him(cl) } & \text { stop(2sg fut) } & \text { after that not have(3sg fut) } & \text { done } \\ \text { qualche } & \text { sciocchezza. } & & & \\ \text { some } & \text { folly } & & \\ \text { 'You will stop him after he has not done something silly.' }\end{array}$

\subsubsection{Distribution of $n$-words and other NPIs}

We have seen in Sect. 2.4 that prima licenses NPIs in its complement. I repeat some examples, involving the NPIs alcuno ('anyone') and alcunché ('anything'):

(56)a. Andai via prima che arrivasse alcuno di loro.

'I went away before anyone of them arrived.'

b. Andai via prima che accadesse alcunché.

'I went away before anything happened.'

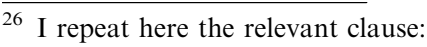

$$
\llbracket \text { più } \rrbracket=\lambda P P_{<\mathrm{d}, \mathrm{t}>} \cdot \lambda Q_{<\mathrm{d}, \mathrm{t}>} \cdot \exists d[\neg P(d) \wedge Q(d)]
$$


On my analysis of prima, these data are straightforwardly accounted for. By the semantic interpretation of the comparative marker più which features in the underlying representation of prima, the complement of prima ends up in the scope of negation. If we follow Ladusaw (1979) in assuming that NPIs are licensed only in the semantic scope of a DE operator, we have an explanation of the sentences given above. On my analysis, sentences $(56 \mathrm{a}, \mathrm{b})$ get the LF-representations (57) and (58), respectively:

(57) [IP [DegP più [CP che $_{2} \exists_{3}\left[\left[\text { Past }_{0} \text { [DP alcuno di loro }\right]_{7}\left[\lambda_{7} \operatorname{arrivare}_{3} x_{7}\right]\right]$

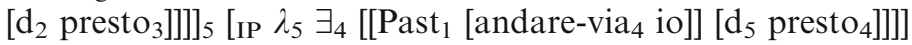

[IP [DegP più [CP che $_{2} \exists_{3}\left[\left[\right.\right.$ Past $_{0}[\mathrm{DP} \text { alcunché }]_{7}\left[\lambda_{7}\right.$ [accadere $\left.\left._{3} x_{7}\right]\right]$

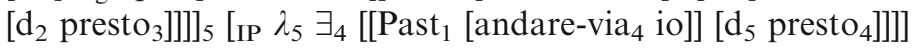

These LFs show that the NPIs alcuno and alcunche end up in the first argument of the comparative marker più. They are thus interpreted as existential quantifiers in the scope of a negative operator, as is shown by the semantic representations $\left(57^{\prime}\right)$ and $\left(58^{\prime}\right)$ :

$$
\begin{aligned}
& \exists d\left[\neg\left(\exists e_{3}\left(\operatorname{Past}_{0}\left(e_{3}\right) \wedge \exists x_{7} \operatorname{arrivare}\left(x_{7}, e_{3}\right) \wedge \operatorname{presto}^{\prime}\left(e_{3}, d\right)\right)\right) \wedge\right. \\
& \left.\left.\exists e_{4}\left(\operatorname{Past}_{1}\left(e_{4}\right) \wedge \text { andare-via(io, } e_{4}\right) \wedge \operatorname{presto}^{\prime}\left(e_{4}, d\right)\right)\right]
\end{aligned}
$$

$$
\begin{aligned}
& \exists d\left[\neg\left(\exists e_{3}\left(\operatorname{Past}_{0}\left(e_{3}\right) \wedge \exists x_{7} \operatorname{accadere}\left(x_{7}, e_{3}\right) \wedge \operatorname{presto}^{\prime}\left(e_{3}, d\right)\right)\right) \wedge\right. \\
& \left.\exists e_{4}\left(\operatorname{Past}_{1}\left(e_{4}\right) \wedge \text { andare-via }\left(\text { io, } e_{4}\right) \wedge \operatorname{presto}^{\prime}\left(e_{4}, d\right)\right)\right]
\end{aligned}
$$

Ladusaw's condition on the interpretability of NPIs is then satisfied for the occurrences of alcuno and alcunché in $(56 \mathrm{a}, \mathrm{b})$.

In Sect. 2.4 we have also seen that prima can license the $n$-words nessuno ('nobody') and niente ('nothing') in its complement with the NPI interpretations of 'anybody' and 'anything', respectively. The following sentences, repeated from Sect. 2.4, are cases in point:

(59)a. Ho scoperto io quel locale, prima che nessuno di voi vi avesse mai messo piede.

'I discovered that place, before anyone of you had ever set foot there.'

b. Me ne andai prima che accadesse niente di spiacevole.

'I left before anything unpleasant happened.'

I assume, following Laka Mugarza (1990), that $n$-words have the status of NPIs, i.e. they get existential interpretations in suitable DE contexts. Unlike her, however, I make the further assumption that the licensing conditions of these elements are more restrictive than those of NPIs such as alcuno/ alcunché, the reason being the plain unacceptability of sentences like $(60 \mathrm{~b}, \mathrm{~d})$ 
below, which sharply contrast with the acceptable sentences $(60 \mathrm{a}, \mathrm{c}) .^{27}$ Sentences $(60 \mathrm{a}-\mathrm{d})$ all involve the downward entailing DP poche persone ('few persons').

(60)a. Poche persone hanno visto alcun film di Hitchcock.

'Few persons have seen any film by Hitchcock.'

b. *Poche persone hanno visto nessun film di Hitchcock.

c. Poche persone hanno notato alcunché di strano.

'Few persons have noticed anything strange.'

d. *Poche persone hanno notato niente di strano.

My further assumption about $n$-words is that they must be interpreted within the scope of an anti-additive operator. ${ }^{28}$ Recall that in my analysis an underlying negation takes scope over the complement of prima; therefore prima is predicted to create not only a DE context, but also an anti-additive one. This fact about prima is all we need for giving an account of the occurrences of nessuno and niente in $(59 \mathrm{a}, \mathrm{b})$.

\subsubsection{Association with the scalar adverb ancora}

The adverb ancora, when it modifies a comparative, triggers the presupposition that the eventuality reported by the subordinate clause of the comparative is ranked high on the scale which is associated with the gradable predicate occurring in the comparative. Let's consider a concrete example:

(61) Leo è ancora più intelligente di Gianni.

'Leo is even more intelligent than Gianni.'

Now, the truth-conditional meaning of (61) is just the same as that of the unmodified comparative Leo è più intelligente di Gianni, but the modified comparative has a presupposition that the latter lacks, namely that there is a standard of intelligence with respect to which Gianni is intelligent and which is significantly high on the intelligence scale. This presupposition, together with the truth-conditional meaning of (61), gives rise to the inference that Leo's intelligence is remarkable. Note that the unmodified version of (61) does not have this entailment either.

\footnotetext{
${ }^{27}$ My assumption that $n$-words have a narrower distribution than NPIs converges with previous studies on this subject. See Blaszczak (2001), Herburger (2001), and Zeijlstra (2004).

${ }^{28}$ Anti-additive operators, as defined in Zwarts (1998), are a sub-set of the set of DE operators. Their defining condition is given by the following equation:

(i) $\mathrm{Op}(\mathrm{X} \cup \mathrm{Y})=\mathrm{Op}(\mathrm{X}) \cap \mathrm{Op}(\mathrm{Y})$

DE operators which are not anti-additive satisfy only the left-to-right component of (i), namely the condition:
}

(ii) $\mathrm{Op}(\mathrm{X} \cup \mathrm{Y}) \subset \mathrm{Op}(\mathrm{X}) \cap \mathrm{Op}(\mathrm{Y})$ 
We can check the correctness of this picture by considering the status of a discourse in which a comparative modified by ancora follows a sentence which negates that the second term of comparison of the comparative is ranked high on the relevant scale. Take example (62):

(62) ?Gianni è poco intelligente. Leo è ancora più intelligente di Gianni.

'Gianni is not very intelligent. Leo is even more intelligent than Gianni.'

The anomaly of (62) is totally expected, given the characterization of the presuppositions of ancora that I have assumed.

Interestingly, we can apply the same kind of test exemplified by (62) to test the correctness of my analysis of prima. If prima has the meaning of the comparative più presto, then we should expect that (63) presupposes that the event of Gianni's arrival is ranked high on the scale associated with presto (hence, that the event in question is located at a time point which is towards the beginning of the relevant time interval).

(63) Leo è arrivato ancora prima di Gianni.

'Leo arrived even earlier than Gianni.'

This expectation actually meets the facts. Sentence (63) does have the presupposition that Gianni's arrival is ranked high on the scale associated with presto, as the anomaly of the following discourse shows:

(64) ?Gianni non è arrivato tanto presto. Leo è arrivato ancora prima di Gianni. 'Gianni didn't arrive very early. Leo arrived even before Gianni.'

So far, so good. But why does scalar ancora fail to associate with dopo? The explanation I propose runs as follows: a dopo-sentence could not serve as a means to express a comparison between two events relative to their respective degrees of lateness; since dopo is an atomic predicate which simply conveys the idea of an event following another, a dopo-sentence modified by scalar ancora could not presuppose that the subordinate event were ranked high on the lateness scale, nor on any other scale. From this explanation, it follows that the occurrence of scalar ancora in a sentence like (65) below is vacuous: this sentence contains a semantically inert word, whose occurrence is not motivated by anything in its structure (this sentence is ruled out since ancora requires a certain presupposition which cannot be computed from the structure of (65)).

*Leo è arrivato ancora dopo Gianni.

If dopo really had the meaning of the comparative più tardi, it should be able to associate with scalar ancora, in the same way as prima does, and we would have 
reason to expect sentences like (65) above to be fully acceptable and to have a particular presupposition which parallels the one triggered by ancora in a sentence like (63) above. The interesting fact is that the modified comparative in (66) is acceptable, and has the presupposition "high ranking on the lateness scale" for the second term of comparison (the event of Gianni's arriving). This fact shows once more that dopo does not express a degree-based comparison.

\section{Conclusion and open problems}

In this paper, I proposed two structurally different analyses of the temporal connectives prima and dopo. This "dualistic" proposal may have appeared strongly counterintuitive, insofar as it clashes with the robust pretheoretical idea that prima and dopo have the same kind of meaning, namely that they stand for two temporal relations, and furthermore that these relations are converse to each other: if prima denotes the relation $t_{1}$ precedes $t_{2}$, then dopo will denote the relation $t_{1}$ follows $t_{2}$. An analysis that follows this intuition will assume that prima and dopo belong to the same syntactic category, and will accordingly ascribe meanings of the same semantic type to them. As far as I know, a uniform analysis of this type, though supported by intuitions, has never been stated in a formal way for Italian. However, it is precisely what underlies the recent proposal by Beaver and Condoravdi (2003) for a uniform analysis of before and after, in which the authors are led by the idea that the two English connectives denote relations that are converse to each other.

I argued that there are language-internal reasons for departing from the pretheoretical idea and the related analysis. What has been gained, I believe, from going dualistic is a principled explanation of a class of different, apparently unrelated phenomena. It is not clear how the many grammatical asymmetries described in this paper could be accounted for while sticking to a uniform syntactic and semantic analysis of prima and dopo.

In what follows, I will focus on a theoretical issue which is left open by the present proposal. The comparative analysis fares well in predicting that prima is non-veridical. On the other hand, it seems to be too liberal insofar as it makes any prima-sentence true, provided that the main clause of the sentence is true and the temporal clause false. This prediction comes about regardless of the unrelatedness of the two clauses. An example showing this shortcoming is sentence (67), whose predicted truth conditions are given in (68):

(67) ?Mozart morì prima che volasse sulla Luna.

'Mozart died before he flew to the Moon.'

$$
\begin{aligned}
& \exists d\left[\neg\left(\exists e_{3}\left(\operatorname{Past}_{0}\left(e_{3}\right) \wedge \operatorname{Mozart-fly-to-Moon}\left(e_{3}\right) \wedge \operatorname{presto}^{\prime}\left(e_{3}, d\right)\right)\right) \wedge\right. \\
& \left.\exists e_{4}\left(\operatorname{Past}_{1}\left(e_{4}\right) \wedge \operatorname{Mozart-die}\left(e_{4}\right) \wedge \operatorname{presto}\left(e_{4}, d\right)\right)\right]
\end{aligned}
$$


Intuitively, (67) is anomalous, but it is predicted to be true on the analysis given in (68). ${ }^{29}$ Following Beaver and Condoravdi's (2003) diagnosis of the oddity of similar examples in English, we can assume that the strangeness of (67) depends on the falsity of a counterfactual conditional which is implied by (67). The conditional is the following:

(67') If Mozart had not died when he in fact did, he might/would have flown to the Moon.

Indeed, $\left(67^{\prime}\right)$ is plainly incompatible with our shared beliefs about Mozart.

Now, the comparative analysis (in its present form) can not distinguish between the odd sentence (67) and the felicitous and true sentence (69): ${ }^{30}$

(69) Mozart morì prima che terminasse la Messa da Requiem.

'Mozart died before he finished the Requiem.'

This shortcoming may be overcome by suitably modalizing the comparative analysis of prima, without giving up its main syntactic insights. The comparative analysis was cast in a purely extensional framework: no quantification over possible worlds was introduced as part of the semantic contribution of prima, and no branching structure was associated with the scale of earliness degrees, which I have assumed to be the same as the linearly ordered structure of time instants.

Here, I will suggest a possible implementation of the comparative analysis in a slightly revised framework, one in which the syntactic assumptions are kept constant, whereas the semantic model is modified so as to allow for a branching structure of moments of time. ${ }^{31}$ In the revised framework, the set of times $\mathrm{T}$ is ordered by a tree-like relation, where branching is only rightward, i.e. towards the future. This is intended to represent the idea that, for any time $t$, the past of $t$ is settled and determined in only one possible way (the set of times earlier than $t$ is linearly ordered), while the future of $t$ is open to many possible developments. A branch is defined as a subset of $\mathrm{T}$ which is linearly ordered and is maximal for inclusion. Branches represent possible courses of events (corresponding to the possible worlds of classical intensional semantics). A further assumption is that for any time $t \in \mathrm{T}$ there exists a set $\mathrm{H}_{t}$ containing all and only the times $t^{\prime}$ such that $t^{\prime}$ lies on some branch passing through $t$. Adapting an idea from Beaver and Condoravdi (2003), I assume that the branches passing through $t$ (where $t$ is any time belonging to some branch $b$ ) represent the courses of events $b^{\prime}$ which satisfy the following conditions:

\footnotetext{
${ }^{29}$ In predicting (67) to be true, the present analysis is similar to the universal quantifier analysis of before, which has indeed been criticized by some authors in this respect (see Ogihara 1995; Beaver and Condoravdi 2003).

30 Example (69) is adapted from Beaver and Condoravdi (2003).

31 The modal version which I briefly sketch here is related to ideas expressed in Bonomi (2005).
} 
(a) $b^{\prime}$ is indistinguishable from $b$ up to, but not including, time $t$ (initial branch point condition of Beaver and Condoravdi);

(b) $b^{\prime}$ is reasonably probable given the course of events up to $t$ (normality condition of Beaver and Condoravdi).

In the revised analysis, the domain of the universal quantifier over degrees corresponding to the subordinate clause can be restricted along the following lines:

A sentence of the form 'A prima che B' is interpreted as the quantification over degrees ' $\exists d\left[\forall d^{\prime} \in \mathrm{H}_{d}\left[\exists e\left[\mathrm{~B}(e) \wedge \operatorname{presto}\left(e, d^{\prime}\right)\right] \rightarrow d^{\prime}<d\right] \wedge\right.$ $\exists e^{\prime}\left[\mathrm{A}\left(e^{\prime}\right) \wedge\right.$ presto $\left.\left.\left(e^{\prime}, d\right)\right]\right]$, where the restrictor set $\mathrm{H}_{d}$ is as specified above.

The oddity of (67) is then explained as a case of presupposition failure, where the failed presupposition is the familiar one which requires quantificational domains of strong quantifiers not to be empty. ${ }^{32}$ Indeed, the domain of the restricted universal quantifier ' $\forall d_{1} \in \mathrm{H}_{d}$ ' in the revised representation (70) is empty:

$$
\begin{aligned}
& \exists d\left[\forall d _ { 1 } \in \mathrm { H } _ { d } \left[\exists e _ { 3 } \left[\operatorname{Past}_{0}\left(e_{3}\right) \wedge \operatorname{Mozart-fly-to-Moon}\left(e_{3}\right) \wedge\right.\right.\right. \\
& \left.\left.\operatorname{presto}^{\prime}\left(e_{3}, d_{1}\right)\right] \rightarrow d_{1}<d\right] \wedge \exists e_{4}\left[\operatorname{Past}_{1}\left(e_{4}\right) \wedge \operatorname{Mozart-die}\left(e_{4}\right) \wedge\right. \\
& \left.\left.\operatorname{presto}^{\prime}\left(e_{4}, d\right)\right]\right]
\end{aligned}
$$

The set $\left\{d_{1} \in \mathrm{H}_{d}: \exists e_{3}\left[\operatorname{Past}_{0}\left(e_{3}\right) \wedge \operatorname{Mozart-fly-to-Moon}\left(e_{3}\right) \wedge \operatorname{presto}^{\prime}\left(e_{3}, d_{1}\right)\right]\right\}$ turns out to be empty for the following reason: moments in the set $\mathrm{H}_{d}$ belong to courses of events $b$ such that $b$ is like the actual course of events up to, but not including, the time of Mozart's death $d$, and $b$ is reasonably probable given the facts up to time $d$; but there is no such course of events in which Mozart flies to the Moon.

This brief suggestion indicates a way in which the present analysis could be improved so as to take into account presuppositional phenomena which have not been in the focus of this paper, but should be handled in a more comprehensive study.

\section{References}

Anscombe, G.E.M. 1964. Before and after. The Philosophical Review 73(1): 3-24.

Beaver, D., and C. Condoravdi. 2003. A uniform analysis of before and after. In Proceedings from SALT 13, 37-54. Ithaca, NY: CLC Publications.

Blaszczak, J. 2001. Investigation into the interaction between the indefinites and negation. Studia Grammatica. Berlin: Akademie Verlag.

Bonomi, A. 2005. The gradable predicate 'actuale'. Ms, University of Milan.

Bresnan, J. 1973. Syntax of the comparative clause construction in English. Linguistic Inquiry 4: $275-343$.

\footnotetext{
32 For a discussion of the existence presuppositions associated with quantifiers in natural language, see Heim and Kratzer (1998, pp. 162-172).
} 
Corblin, F., and L.M. Tovena. 2003. L'expression de la négation dans les langues romanes. In Les langues romanes: problemes de la phrase simple, ed. D. Godard, 281-343. Paris: CNRS Editions.

Cresswell, M.J. 1976. The semantics of degree. In Montague grammar, ed B.H. Partee, 261-292. New York: Academic Press.

Donati, C. 2000. La sintassi della comparazione. Padova: Unipress.

Espinal, M.T. 2000. Expletive negation, negative concord and feature checking. Catalan Working Papers in Linguistics 8: 47-69.

Heim, I. 1999. Notes on superlatives. Ms, MIT.

Heim, I., and A. Kratzer 1998. Semantics in generative grammar. Malden \& Oxford: Blackwell.

Heinämäki, O. 1974. Semantics of English temporal connectives. PhD dissertation, University of Helsinki (reproduced by Indiana University Linguistics Club, 1978).

Herburger, E. 2001. The negative concord puzzle revisited. Natural Language Semantics 9: 289-333.

Higginbotham, J. 1988. Is semantics necessary? Proceedings of the Aristotelian Society 87: 219-241.

Ladusaw, W.A. 1979. Polarity sensitivity as inherent scope relations. PhD dissertation, University of Texas at Austin.

Laka Mugarza, I. 1990. Negation in syntax: On the nature of functional categories and projections. $\mathrm{PhD}$ dissertation, MIT.

Landman, F. 1991. Structures for semantics. Dordrecht: Kluwer.

Longobardi, G. 1986. In defense of the "Correspondence Hypothesis": Island effects and parasitic gap construction in logical form. Ms, Scuola Normale Superiore, Pisa.

Ogihara, T. 1995. Non-factual before and adverbs of quantification. In Proceedings from SALT 5, 273-291. Ithaca, NY: DMLL Publications, Cornell University.

Parsons, T. 1985. Underlying events in the logical analysis of English. In Actions and events: Perspectives on the philosophy of Donald Davidson, ed. E. LePore and B. McLaughlin, 235-267. Oxford: Basil Blackwell.

Parsons, T. 1990. Events in the semantics of English: A study in subatomic semantics. Cambridge, MA: MIT Press.

Seuren, P.A.M. 1973. The comparative. In Generative grammar in Europe, ed. F. Kiefer and N. Ruwet, 528-564. Dordrecht: Reidel.

Valencia, V.S., T. van der Wouden, and F. Zwarts. 1994. Polarity, veridicality, and temporal connectives. In Proceedings of the Ninth Amsterdam Colloquium, ed. P. Dekker and M. Stokhof, 587-606. University of Amsterdam.

von Stechow, A. 1984. Comparing semantic theories of comparison. Journal of Semantics 3: 1-77. von Stechow, A. 2006. Times as degrees: früh(er) 'early(er)' / spät(er) 'late(r)', and phase adverbs. Ms, Universität Tübingen. Paper available at http://vivaldi.sfs.nphil.uni-tuebingen.de/ $\sim \operatorname{arnim} 10 /$.

Zanuttini, R. 1989. The structure of negative clauses in Romance. Ms, University of Pennsylvania. Zeijlstra, H. 2004. Sentential negation and negative concord. Utrecht: LOT.

Zwarts, F. 1998. Three types of polarity. In Plurality and quantification, ed. F. Hamm and E. Hinrichs, 177-238. Dordrecht: Kluwer. 